Review

\title{
Recent advances in the electrocatalytic application of transition metal nitrides nanocrystalline
}

\author{
Shuhong Zheng ${ }^{1,2} \neq$, Ren Luo ${ }^{2.3 \ddagger}$, Zihan Meng ${ }^{2,3}$, Rui Wang ${ }^{1,2}$, Hongyun Tan ${ }^{2,3}$, Yannan Xia ${ }^{2,3}$ and Haolin Tang ${ }^{1,2,3^{*}}$ \\ 1 State Key Laboratory of Advanced Technology for Materials Synthesis and Processing, Wuhan University of \\ Technology, Wuhan 430070, China \\ 2 Foshan Xianhu Laboratory of the Advanced Energy Science and Technology Guangdong Laboratory, \\ Xianhu Hydrogen Valley, Foshan 528200, China \\ 3 Guangdong Hydrogen Energy Institute of WHUT, Xianhu Hydrogen Valley, Foshan 528200, China \\ * Address correspondence to Haolin Tang, thln@whut.edu.cn \\ ‡ These authors contributed equally to the work.
}

\begin{abstract}
The energy crisis and environmental problems are becoming more and more severe due to the long-term consumption of fossil fuels. Therefore, energy conversion devices with high energy density and environmental friendliness (such as fuel cells, metal-air batteries, etc.) have been expected to be reliable alternatives to traditional fossil energy. However, due to the inevitable use of precious metals as the electrode catalysts for these devices, the popularization of these alternatives is seriously hindered. Transition metal nitrides (TMNs) exhibit similar surface and adsorption properties to noble metals since the atomic distance between metal atoms increases and the d-band center of metal atoms downshift after the nitrogen atoms enter the metal lattice. TMNs have become one of the best electrode materials to replace noble metal electrocatalysts in energy storage and conversion devices. In this review, the latest development in the electrocatalytic application of TMNs nanocrystalline is covered. Firstly, we briefly discuss the structure and activity origin of TMNs and introduce the common physical and chemical methods for the preparation of TMNs. Subsequently, we illustrate the applications of unary TMNs and multivariate TMNs in oxygen reduction reaction (ORR) and oxygen evolution reaction (OER). Finally, we summarize the challenges and problems of TMNs encountered at the present stage, and expect its future development.
\end{abstract}

Keywords: Transition metal nitrides, Preparation methods, Electrocatalytic application, Oxygen reduction reaction, Oxygen evolution reaction.

\section{Introduction}

With the rapid development of society and the economy, the demand for energy is increasing in recent years. The environmental pollution caused by the use of fossil fuels is becoming increasingly severe. Human beings are facing unprecedented energy shortage and environmental pollution problems.[1-3] Therefore, human society is now facing the challenge to get rid of the dependence on traditional fossil energy, develop new and efficient energy conversion devices, and transform the energy mode. At the same time, the development of energy shortage and conversion devices, such as fuel cells and metal-air batteries, has also provided strategies to solve the energy shortage and environmental pollution.[4-6] Taking the fuel cell as an example, on account of it uses hydrogen as the fuel and the reaction product is water, it has almost no pollution to the environment. Besides, because it gets rid of the restrictions of the Carnot cycle, it also shows a high energy conversion efficiency. Therefore, the fuel cell has become a hot research object for the researchers from many fields.[7, 8] For both fuel cells and metal-air batteries, their internal reaction is generally composed of two parts, one is the fuel oxidation reaction in the anode, the other is ORR in the cathode, and these two reactions occur all need suitable electrocatalysts to reduce reaction barrier. $[9,10]$ At present, the commercial application of fuel cells and other new energy devices are based on Pt-based materials loaded with carbon black 
as the electrocatalysts for both cathode and anode, but due to the scarcity of Pt resources and high price, the cost of these new energy conversion devices is expensive, which significantly restricts their industrialization.[11, 12] In particular, compared with hydrogen oxidation reaction (HOR) in the anode, ORR in the cathode involves two-electron and four-electron transfer process of oxygen, it has higher reaction barrier, more complex reaction process and slower reaction rate. For example, the rate of ORR in the cathode is generally only $1 / 10^{6}$ the speed of HOR in the anode in a fuel cell, so the loading of $\mathrm{Pt}$ in the cathode is even more.[13-17] Therefore, how to reduce the cost of electrocatalysts and find low-cost electrocatalyst materials to replace precious metals electrocatalysts are of vital importance for the development, application, and popularization of these novel energy conversion devices.

Thanks to the metal-metallic bond rearrangement, the formation of the new chemical bond between the metal and non-metal atom, and the electron transfer between metal and non-metal atoms, TMNs nanocrystal materials are characterized by covalent compounds, ionic crystals, and transition metals, and have great application value in catalysis, energy storage and conversion, super-hard materials, semiconductors and superconductors.[18, 19] Due to the introduction of highly electronegative nitrogen element, the nitrogen atoms fill in the interstitial places of the metal cells, thereby TMNs form interstitial compounds or alloy structures.[20] Besides, nitrogen atoms enter into the interstitial sites of nanocrystal cell, which results in the increase of the transition metal atoms spacing, the expansion of the lattice, the shrinkage of transition metal d- band, and the increase of Fermi level state density. And the redistribute of Fermi level state density makes their electrocatalytic activity and surface properties different from those of the parent metal, and are similar to the eighth group precious metals (such as Pt).[21] These changes give the TMNs excellent conductivity, electrocatalytic activity and optical properties, couple with its corrosion resistance and high-temperature resistance, so that TMNs are available to be used in electrocatalysis, petroleum hydrodesulphurization, ammonia synthesis and decomposition, hydrogen production catalysis, and other fields.[22, 23]

In recent years, researchers have found that downsizing materials to the nanoscale can often give them unusual mechanical, electrical, and optical properties.[24, 25] Hence, the study of nanostructured electrocatalyst materials has aroused great interest. Besides, due to the high price of Pt, the U.S. Department of Energy set the goal of electrocatalyst in 2017, namely, improving the ORR activity of fuel cell cathode electrocatalyst, and further reducing the amount of Pt loaded.[26] Therefore, the design idea of using tiny nanoparticles as electrocatalysts has gradually been considered by the researches. As all we know, the ideal electrode materials should also have an excellent ability for electronic conductivity and ionic conductivity, the design idea of using nanoparticles as the materials for electrocatalyst can not only significantly reduce the consumption of rare and expensive metals, but also improve the ionic conductivity of materials by shortening the diffusion length of ions in catalytic materials. Therefore, the design of nanostructures for electrode materials can significantly improve the electrical properties of materials.[27] Moreover, when the electrocatalyst is discrete nanoparticles or polycrystalline thin films, the dynamics of material activity can be changed almost one order of magnitude. The unique nanostructure will provide new features of the electrocatalyst material surface, which can significantly improve the activity of electrocatalyst materials, and lead to large specific surface area and more adsorption and reaction sites.[26] Therefore, the design of TMNs nanocrystalline is an important research field for electrode catalysts of energy shortage ang conversion devices. In this paper, some preparation methods and structural characteristics of TMNs nanocrystals are reviewed. Their applications (ORR and OER) to electrode materials of some new energy devices are briefly reported and summarized. Finally, the development opportunities and challenges of TMNs nanocrystals in the future are discussed. 


\section{Preparation methods and structural properties of TMNs}

Due to its excellent performance as a highly effective electrocatalyst, TMNs have undoubtedly attracted the attention and interest of the scholars. However, the study and discussion on their preparation are still relatively few at present, and the synthetic strategies are relatively limited.[27] The synthetic methods of TMNs can be mainly divided into physical methods and chemical methods (Figure. 1), the former include laser ablation, sputtering, arc discharge, physical vapor deposition, etc., and the latter include direct nitriding of transition metals, nitriding of transition metals oxides, ammonolysis of transition metals chloride, solvothermal method, thermal decomposition of polymer precursors, etc.[28]

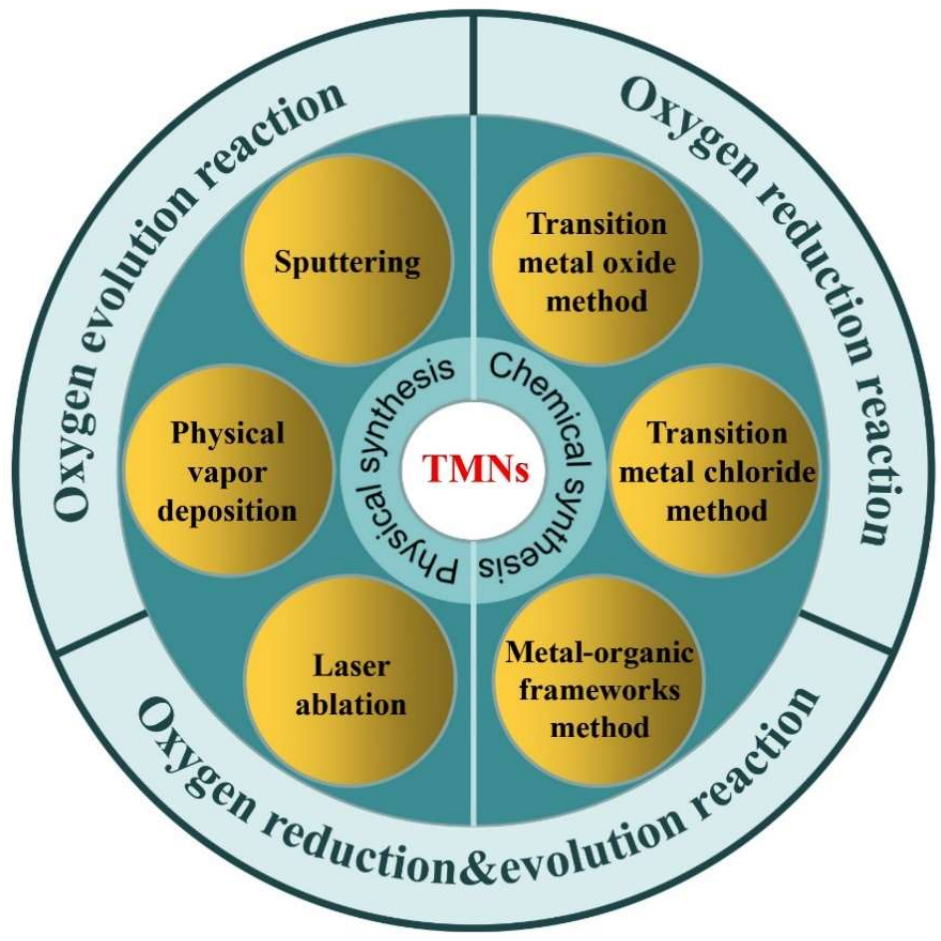

Figure. 1 Simple diagram of the synthetic methods and applications of TMNs.

\subsection{Physical synthetic methods}

The primary method used for most physical syntheses is deposition, and the sample is mainly in the form of thin film; that is, different physical means are used to load the reactants onto the substrate. Physical vapor deposition (PVD) technology is a relatively popular deposition method at the present stage. PVD refers to using physical processes (such as thermal evaporation of material) to make the surface of source material vaporize, under vacuum conditions, atoms, molecules or partially ionize ions which are then deposited to form a film with some special functions on the surface of the substrate through low pressure, thus realizing the control of atom transfer from source materials to coatings.[29]

PVD technology is often combined with some other physical means (such as sputtering, ion irradiation, etc.) to synthesize TMNs. Sputtering is the most commonly used physical synthesis method due to its high deposition rate, which requires the sputtering gas (argon) and the reaction gas (nitrogen) to prepare high purity thin film samples with controllable stoichiometry and composition by PVD. For instance, Zhu et al.[30] successfully deposited cubic, wurtzic, and explosive high-pressure phases boron nitride films on the metal alloy substrates by tuned substrate radio frequency magnetron sputtering and PVD 
techniques. The percentage of cubic boron nitride phase in the film was about $50 \%$ as calculated by Fourier transform infrared measurements. Compared with the cubic phase formed by the traditional low energy ion bombardment, the cubic boron nitride phase prepared by this method had a very low internal stress, which could perfectly solve poor adherence and delamination from the substrates. Wei et al.[31] equipped bimetallic carbon paper supported vanadium-molybdenum nitride (MoVN) thin films by magnetron co-sputtering. Murthy et al.[32] also designed a series of $\mathrm{Mo}_{3} \mathrm{~N}_{2}, \mathrm{Ag}-\mathrm{Mo}_{3} \mathrm{~N}_{2}, \mathrm{~V}-\mathrm{Mo}_{3} \mathrm{~N}_{2}$ and $\mathrm{CuMo}_{3} \mathrm{~N}_{2}$ films by magnetron co-sputtering technique. Kang et al.[33] prepared $\mathrm{NiN}$ thin films with cauliflower shape and tetrahedral crystal lattice by reactive sputtering in $\mathrm{N}_{2}$ atmosphere.

In addition to sputtering, PVD is also used in combination with ion irradiation, known as ion mixing and vapor deposition (IVD), which can easily change and design the physical and chemical properties of thin films. For example, Uchida et al.[34] used the IVD technique to prepare Titanium aluminum nitride (Ti, Al)N films by depositing $\mathrm{Ti}$ and $\mathrm{Al}$ metal vapor under simultaneous irradiation $\mathrm{N}$ ions. And Liu et al.[29] also successfully prepared a novel quaternary $(\mathrm{Ti}, \mathrm{Al}, \mathrm{Zr}) \mathrm{N}$ coating on $\mathrm{Si}_{3} \mathrm{~N}_{4}$ ceramic substrates by using PVD technology and multi-arc ion plating technique. When the gas pressure was $2.5 \mathrm{~Pa}$, the $(\mathrm{Ti}, \mathrm{Al}, \mathrm{Zr}) \mathrm{N}$ coated $\mathrm{Si}_{3} \mathrm{~N}_{4}$ cutting tools had the most extended lifetime and the best mechanical performance. Although these physical methods can give a definite structure to TMNs, for the majority of TMNs synthesis, the conditions of physical synthetic methods are harsh, the preparation process is cumbersome and inefficient, so it is not suitable for the general synthesis of TMNs.[35]

\subsection{Chemical synthetic methods}

The chemical synthesis of TMNs is generally divided into two steps. Firstly, the precursors of TMNs are synthesized with different methods. Then the metal precursors are nitrided with $\mathrm{NH}_{3}$ or $\mathrm{N}_{2} / \mathrm{H}_{2}$ mixed gases at different temperatures to obtain various forms of TMNs.[36] Therefore, according to the different types of precursor materials, the chemical process for TMNs synthesis can be divided into the transition metal oxide method, transition metal chloride method, metal-organic frameworks method, and other methods.

\subsubsection{Transition metal oxide method}

Transition metal oxides (TMOs), as the most common compound form of transition metal, are nitrided to prepare TMNs, which is relatively common way to synthesize TMNs at present. [37] The specific experimental procedure is to oxidize the transition metal into TMOs, or directly use TMOs crystals before hot ammonia reduction.[38] The calcination temperature is usually between $300-800{ }^{\circ} \mathrm{C}$, so that TMNs of different dimensions can be obtained. Due to the fact that the oxygen atom is used to replaces the nitrogen atom in the lattice, the lattice volume shrinks. Hence, it is easy to generate many mesoporous structures on the surface of TMNs prepared by TMOs. This method can be used to prepare mesoporous TMNs. For example, Peng et al.[39] nitrided $\mathrm{TiO}_{2}$ nanotubes array into $\mathrm{TiN}$, and used the resulted porous TiN nanotube array as the core to prepare TiN-core porous double-layer $\mathrm{MoO}_{x}\left(\mathrm{MoO}_{x} / \mathrm{TiN} / \mathrm{MoO}_{x}\right)$ nanotube array with high conductivity. The porous structure facilitated the electrolyte infiltration, and the maximizing of exposure to the reaction sites of the material. Simultaneously, the high conductivity of TiN gave the material a high specific capacitance. Nagai et al.[40] used a temperature-programmed reaction to convert $\mathrm{MoO}_{3}$ to $\mathrm{Mo}_{2} \mathrm{~N}$ in the atmosphere of $\mathrm{NH}_{3}$ and $\mathrm{N}_{2} / \mathrm{H}_{2}$ mixture. The resulted electrocatalyst showed an irregular surface with abundant nanopores and high specific surface areas, which had excellent electrocatalytic effect in hydrodenitrification, hydrodesulfurization, hydrolysis and hydrogenation. Similarly, Jiang et al.[41] transformed $\mathrm{MoO}_{3}$ nanowires into mesoporous $\mathrm{Mo}_{3} \mathrm{~N}_{2}$ nanowires with cubic crystal nitrogen-vacancy after annealing at $800{ }^{\circ} \mathrm{C}$ in $\mathrm{NH}_{3}$ atmosphere for 6 hours (Figure. 2a, b). It was found that the mechanism of sodium-ion storage devices was a kind of surface redox reaction, so $\mathrm{Mo}_{3} \mathrm{~N}_{2}$ nanowires with a large specific surface area used as the electrode material of the 
sodium ion storage device would have excellent specific capacity and cycle durability (Figure. 2c, d). In another report, Yang et al.[42] synthesized VN, TiN, NbN, and $\mathrm{Ta}_{3} \mathrm{~N}_{5}$ by passing ammonia through a pipeline containing the oxides of $\mathrm{V}, \mathrm{Ti}, \mathrm{Nb}$, and $\mathrm{Ta}$ under the protection of argon gas at $450-800{ }^{\circ} \mathrm{C}$. However, these preparation operations are often time-consuming. To optimize the synthesis process of TMNs and shorten the synthesis time, Cheng et al.[43] studied a new rapid nitriding process. They synthesized a series of ordered mesoporous TMNs by using mesoporous TMOs. This ordered mesoporous structure promoted the interaction between ammonia and metal oxides precursors, and effectively shortened the nitriding time. It was pointed out that rapid nitriding also inhibits the closure and collapse of mesoporous structures. Besides, the researchers found that amorphous TMOs could also be directly nitrided to produce TMNs. For example, Wang et al.[44] prepared metastable $\mathrm{MoO}_{2}$ using hydrazine reduction $\left(\mathrm{NH}_{4}\right)_{6} \mathrm{Mo}_{7} \mathrm{O}_{24}$ solution. The amorphous $\mathrm{MoO}_{2}$ was converted into face-centered cubic $\gamma-\mathrm{Mo}_{2} \mathrm{~N}$ at $400{ }^{\circ} \mathrm{C}$ ammonia flow, and into hexagonal $\sigma-\mathrm{Mo}_{2} \mathrm{~N}$ at the different temperature of $600{ }^{\circ} \mathrm{C}$.

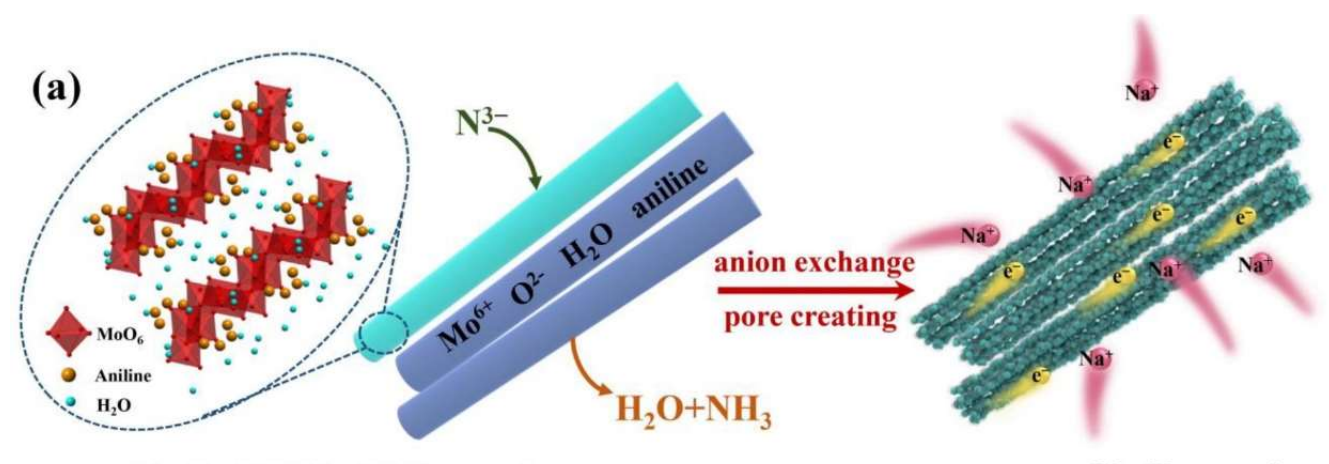

$\mathrm{Mo}_{3} \mathrm{O}_{10}\left(\mathrm{C}_{6} \mathrm{H}_{8} \mathrm{~N}\right)_{2} \cdot 2 \mathrm{H}_{2} \mathrm{O}$ nanowires

mesoporous $\mathrm{Mo}_{3} \mathrm{~N}_{2}$ nanowires
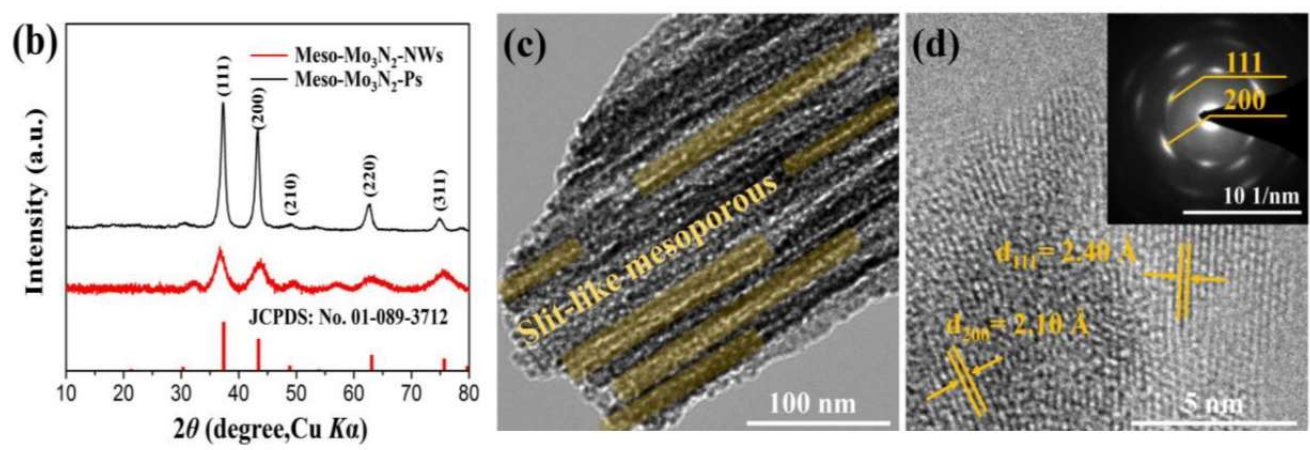

Figure. 2 (a) Schematic of the formation of Meso-Mo3 $\mathrm{N}_{2}-\mathrm{NWs}$; (b) XRD patterns of the Meso$\mathrm{Mo}_{3} \mathrm{~N}_{2}-\mathrm{Ps}$ and Meso-Mo3 $\mathrm{N}_{2}-\mathrm{NWs}$; TEM (c) and HRTEM (d) images of Meso-Mo3 $\mathrm{N}_{2}-\mathrm{NWs}$. Redrawn with permission of ref. 41. Copyright 2021 Elsevier.

The method to prepare TMNs using TMOs as a precursor is relatively mature and widely used; however, general TMOs show relatively more crystal forms. This kind of preparation process usually involves high-temperature conditions. When heated at high temperature, TMOs tends to undergo crystal transformation or transition between crystalline and amorphous states, resulting in incomplete nitriding of the transition metal, and even affecting the final structure of TMNs.

\subsubsection{Transition metal chloride method}

As the reaction temperature of transition metal chloride and ammonia is lower than that of TMOs, it is also widely used for the preparation of TMNs. For example, Choi et al. [45] prepared tantalum and tungsten nitrides through a two-step process. Firstly, the tan- 
talum and tungsten chloride was ammonolyzed in anhydrous chloroform at room temperature. Then, the prepared powder was heat-treated in an ammonia atmosphere to obtain tantalum nitride (TaN and $\left.\mathrm{Ta}_{2} \mathrm{~N}\right)$ and tungsten nitride (WN). Afanasiev et al.[46] also prepared alkaline-earth chloride nanoparticles through chloridizing scheelite with $\mathrm{CCl}_{4}$, which were then ammonolyzed to obtain $\mathrm{MoN}$ and WN. In this manner, the transition metal nitriding could be carried out at a suitable temperature $\left(500-550{ }^{\circ} \mathrm{C}\right)$ which was much lower than the temperature for the traditional ammoniation of TMOs using pure $\mathrm{NH}_{3}$ or $\mathrm{N}_{2} / \mathrm{H}_{2}$ mixtures, and technically easy to achieve. In addition, the transition metal chloride method could also be used to prepare transition metal-nitride nanocomposites. For example, Cheng et al.[47] reported a method for the preparation of transition metal $\mathrm{Si}_{3} \mathrm{~N}_{4}$ composite nanomaterials. They designed the $\mathrm{Si}_{3} \mathrm{~N}_{4}$ complex with palladium chloride and silicon diimide gel as raw materials, and then prepared $\mathrm{Pd}-\mathrm{Si}_{3} \mathrm{~N}_{4}$ nanocomposites with high specific surface area and mesoporous structure. This method could also be used for the preparation of other transition metal $\mathrm{Si}_{3} \mathrm{~N}_{4}$ composites, such as $\mathrm{Ni}, \mathrm{Co}, \mathrm{Zr}$, and $\mathrm{Ru}$. Qiu et al.[48] also reported a new method in which they synthesized various metal nitrides (such as $\mathrm{CrN}, \mathrm{Fe}_{2} \mathrm{~N}$, etc.) using metal-urea chloride as precursors, and this study also facilitated the understanding of the feasibility of metal-urea chloride as a low-temperature synthesis TMNs. Besides, the reaction mechanism was the nucleation growth mechanism, and the use of the metal-urea complex as a precursor to prepare more complex TMNs was also considered adequately. For example, Weil et al.[49] reported a method to prepare TMNs powders and coatings, they dissolved transition metal chlorides in solvents, such as acetonitrile, and reacted with alkanolamine to form a viscous chelating solution as a precursor, and then generated TMNs through heat treatment.

While using ammonium chloride solution synthesis, the temperature needed by TMNs is lower than those of the transition metal oxide nitride method. Nevertheless, the time it takes to ammonium chloride solution is often long. The synthesis process involves the utilization of a large number of organic reagents, steps and process trivial. At this stage, it is only applicable to be used in the lab to synthesize small-scale TMNs for research.

\subsubsection{Metal-organic frameworks method}

In addition to transition metal oxides and chloride, metal-organic frameworks (MOFs) are also commonly used as precursors for TMNs. MOFs are crystalline porous materials with periodic network structure formed by the self-assembly of transition metal ions or metal clusters with organic ligands through coordination bonds or other forces. Due to the unique porous structure of MOFs, TMNs prepared by MOFs as precursor materials generally show a relatively rich pore structure.[50-52] As shown in Figure. 3a-c, CoN with various structures were prepared through different MOFs precursors, and such MOFs-derived TMNs all maintained a common porous structure feature. By the way, in terms of the application of electrocatalysts, a rich pore structure can increase the exposure site of the active center, and improve electrocatalysts' electrocatalytic activity. In recent years, there are many reports on the preparation of TMNs by MOFs. For example, Cheng et al.[53] obtained porous iron nitride (FeN) nanoparticles using cubic crystal MOFs (Prussian blue) as precursors by rapid nitridation process. The FeN samples retained the precursors' structure, and only contracted nominally during the transformation process, thus obtaining a high specific surface area. Zhu et al.[54] synthesized porous $\mathrm{Co}_{3} \mathrm{FeN} \mathrm{N}_{x} / \mathrm{N}$ doped carbon nanotube arrays supported by a carbon cloth through simple nitriding of MOFs (ZIF-67) at room temperature. The synthesized samples showed hierarchically porous structures, which increased the exposure of the activity sites, accelerated the charge/mass transfer, and thus improved the electrocatalytic activity. Moreover, Hu et al.[55] reported a preparation method of manganese nitride $(\mathrm{MnN})$ by cracking manganese triazole in an oxygen-free environment. Wang et al.[56] obtained Co@Co4N/MnO-NC by cracking the Mn-containing molecular sieve-imidazole framework. Liu et al.[57] synthesized FeN using the iron foundation organic frameworks as the hard templates. However, as one of the 
most essential advantages of MOFs, high porosity can also bring a few disadvantages. For instance, in the final stage of synthesis, the organic groups of MOFs disappear with nitriding, leaving their spatial structure only, and the resulted TMNs can still be classified as ceramics. Therefore, the porosity means that both the density and the mechanical strength are reduced, which makes it easily destroyed by external forces in practical application. This still needs to be optimized.

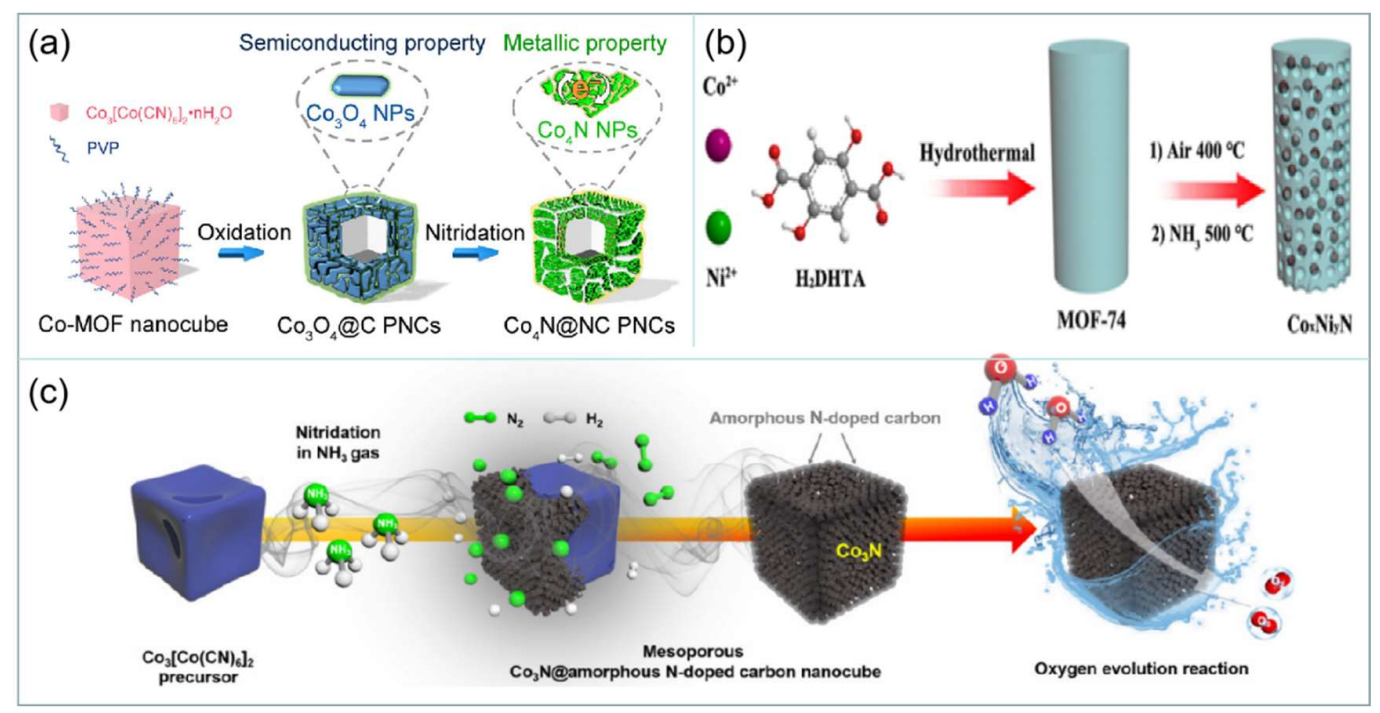

Figure 3 (a) Schematic of the synthesis route of Co4N@NC PNCs; (b) Schematic diagram of the formation of porous CoxNiyN composites; (c) Schematic illustration of the synthesis process of mesoporous Co3N@amorphours N-doped carbon NCs. Redrawn with permission of ref. 50, 51 and 52. Copyright 2018 and 2019 American Chemical Society. Copyright 2019 Tsinghua University Press.

\subsubsection{Other chemical methods}

In addition to the methods mentioned above, many other chemical synthetic ways have been used by researchers to synthesize TMNs. For example, Barker et al.[58] dissolved the metal in liquid zinc, and then the solution reacted with nitrogen to produce binary and ternary nitrides (e.g., $\mathrm{Ca}_{2} \mathrm{ZnN}_{2}$ ). Xiao et al.[59] synthesized two-dimensional $\mathrm{Mn}_{3} \mathrm{~N}_{2}$ by lattice matching method. Yao et al.[60] used urea as a nitrogen source to synthesize various transition metal nitride compounds ( $\mathrm{TiN}, \mathrm{NbN}, \mathrm{Mo}_{2} \mathrm{~N}, \mathrm{~W}_{2} \mathrm{~N}, \mathrm{NbC}_{\mathrm{x}} \mathrm{N}_{1-\mathrm{x}}$ ) in different conditions. In conclusion, various nano-morphology TMNs have been prepared by scholars using other precursors and different nitriding methods. There are still many feasible approaches, which need to be discussed in the future.

\section{Transition Metal Nitrides as electrocatalyst}

Transition metal nitrides are used as the electrocatalysts due to their stable structure, high conductivity, and strong anti-poisoning ability.[61, 62] On one hand, as a kind of interstitial nanocrystal material, TMNs have the characteristics of covalent compounds, ionic crystals, and transition metals due to the rearrangement of metal-metal bonds, the formation of metal and non-metal atoms, and the electron transfer between metal and non-metal atoms. On the other hand, the highly electronegative nitrogen species in the gap results in the increase of the metal atom spacing, shrinkage of the transition metal dband as well as increase of the Fermi level state density. Therefore, the surface properties and adsorption characteristics of some TMNs (Ti, Ni, Fe, Co, Mo, etc.) are similar to those of noble metal. [63-65] Thus, TMNs have high performance in ORR, OER, and other fields. 


\subsection{Transition metal nitrides as ORR electrocatalyst}

At present, the oxygen reduction electrocatalytic process mainly relies on the Ptbased electrocatalyst. However, due to the shortage of Pt resources, and the continuous increase of prices, the dependence of energy conversion devices on precious metals has greatly restricted its industrialization process. TMNs are considered to be one of the most promising alternatives for noble metal ORR electrocatalysts due to their low price, abundant reserves, and comparable electrocatalytic performance.[66, 67]

\subsubsection{Unary TMN}

TMN was first discovered as ORR electrocatalyst in 1964.[68] Jasinski experimentally found that cobalt, cooperating with nitrogen, showed activity for ORR. Since then, TMNs have been widely studied. Yang et al.[69] put forward a simple method to prepare mesoporous $\mathrm{CrN}$ by the ammonolysis of a bulk $\mathrm{K}_{2} \mathrm{Cr}_{2} \mathrm{O}_{7}$, and synthesized $\mathrm{Pt} / \mathrm{CrN}$ electrocatalyst with mesoporous $\mathrm{CrN}$ as the support. The $\mathrm{Pt} / \mathrm{CrN}$ electrocatalyst exhibited higher corrosion resistance and electrochemical active area (ECSA) than the $\mathrm{Pt} / \mathrm{C}$ electrocatalysts, as well as higher ORR activity. This high electrocatalytic activity attributed to the high conductivity and high corrosion resistance of $\mathrm{CrN}$ support, as well as the synergy between CrN support and Pt.

Similarly, Zheng et al.[70] also made a study about TMN serving as the support of precious metal, and synthesized 3D layered porous $\mathrm{Pt} / \mathrm{TiN}$ electrocatalyst by a simple approach. The porous 3D support with higher corrosion resistance and mechanical stability played a key role in improving the conductivity and chemical durability of Pt. Therefore, $\mathrm{Pt} / \mathrm{TiN}$ showed better electrochemical performance than $\mathrm{Pt} / \mathrm{C}$ with a $40 \mathrm{mV}$ negative shift in the half-wave potential $\left(\mathrm{E}_{1 / 2}\right)$. In another report, Yue et al.[71] comparatively studied the electrocatalytic activity and durability of $\mathrm{Pt} / \mathrm{TiN}$ and $\mathrm{Pt} / \mathrm{C}$, and found that $\mathrm{Pt} / \mathrm{TiN}$ electrocatalyst reduced about $22 \%$ of the initial ECSA, which was superior to $66 \%$ ECSA of $\mathrm{Pt} / \mathrm{C}$ after 1000 cycles. At the same time, the $\mathrm{E}_{1 / 2}$ of Pt/TiN (0.85 V) was also higher than that of $\mathrm{Pt} / \mathrm{C}(0.846 \mathrm{~V})$. This brilliant performance was attributed to the fact that the energy levels between Pt-d and N-p states were similar, which facilitated the electron transfer to form Pt-N-Ti bonds.

Besides, TMN is also used as electrocatalyst, Qi et al.[72] synthesized MoN/C and $\mathrm{Mo} 2 \mathrm{~N} / \mathrm{C}$ electrocatalysts and studied the relationship between their structure and ORR activity. This work revealed that the energy gap between the HOMO of MoN/C and the LUMO of $\mathrm{O}_{2}$ was excessively small which brought fast electron transfer between them. As a result, MoN/C exhibited higher ORR electrocatalytic activity compared with Mo2N/C in $\mathrm{O}_{2}$-saturated $0.5 \mathrm{M} \mathrm{HClO}_{4}$.

In addition to the MoN electrocatalyst, Zhang et al.[73] reported a series of novel heterostructure $\mathrm{Ni}_{3} \mathrm{~N}$ quantum dots, which were uniformly distributed on the surface of $\mathrm{NiO}$ nanosheets. According to the electronic structure characterizations, $\mathrm{Ni}_{3} \mathrm{~N}$ QD showed a strong synergy with $\mathrm{NiO}$ nanosheets forming a unique electronic structure around the Fermi level, which not only increased the carrier concentration and conductivity, but also enriched the active sites of oxygen. Thus, the ORR activity of the favorable $\mathrm{Ni}_{3} \mathrm{~N}$ QD/NiO electrocatalyst was comparable to that of $\mathrm{Pt} / \mathrm{C}$.

\subsubsection{Multivariate TMNs}

Although the unary TMN displays impressive electrocatalytic activities, to further enhance the ORR activity, many scholars have conducted on TMN doping. Luo et al.[74] explored the limitations on early-transition-metal nitrides ( $\mathrm{ScN}, \mathrm{TiN}, \mathrm{CrN}$, and $\mathrm{VN}$ ) as competitive electrocatalysts. Then, this work proposed a strategy to enhance its ORR activity by doping with transition metals and synthesized $\mathrm{V}_{0.95} \mathrm{M}_{0.05} \mathrm{Ns}(\mathrm{M}=\mathrm{Cu}, \mathrm{Ni}, \mathrm{Co}, \mathrm{Fe}$, $\mathrm{Mn}, \mathrm{Cr}$, and Ti). Among them, $\mathrm{V}_{0.95} \mathrm{Co} 0.05 \mathrm{~N}$ exhibited the most outstanding ORR performance, with its electron transfer number of the ORR of above 3.8, and the value was competitive with the performance of $20 \mathrm{wt} . \% \mathrm{Pt} / \mathrm{C}$ in alkaline medium.

Tian et al.[75] investigated the effects of the doping elements (Fe, Co, and $\mathrm{Ni}$ ) on $\mathrm{TiN}$ electrocatalytic performance. The experimental data indicated that the doping might have 
impact on the microstructure of the TiN with the vacancy of the d-band of the Ti atom reduction, and its ability to provide electrons to oxygen is increased. Most importantly, the performance of $\mathrm{Ti}_{0.95} \mathrm{Ni} 0.05 \mathrm{~N}$ was almost comparable to that of commercial $\mathrm{Pt} / \mathrm{C}$ in 0.1 $\mathrm{M} \mathrm{KOH}$ solution. Later, Tian et al.[76] continuously studied the effects of the doping cobalt on TiN in electrocatalytic performance. They prepared $\mathrm{Ti}_{0.8} \mathrm{Co} .{ }_{2} \mathrm{~N}$ nanosheets by the solvothermal with post-nitriding approach and found the electronic modification effect caused by $\mathrm{Co}$ doping endowed the $\mathrm{Ti}_{0.8} \mathrm{Co} 0.2 \mathrm{~N}$ electrocatalyst with a remarkable activity with $\mathrm{E}_{1 / 2}$ of $0.85 \mathrm{~V}$ (Figure. 4a-f). The obtained electrocatalyst revealed high durability with only $4 \mathrm{mV}$ shifting of the half-wave potential after the durability test for 5000 cycles (Figure. $4 \mathrm{~g})$.

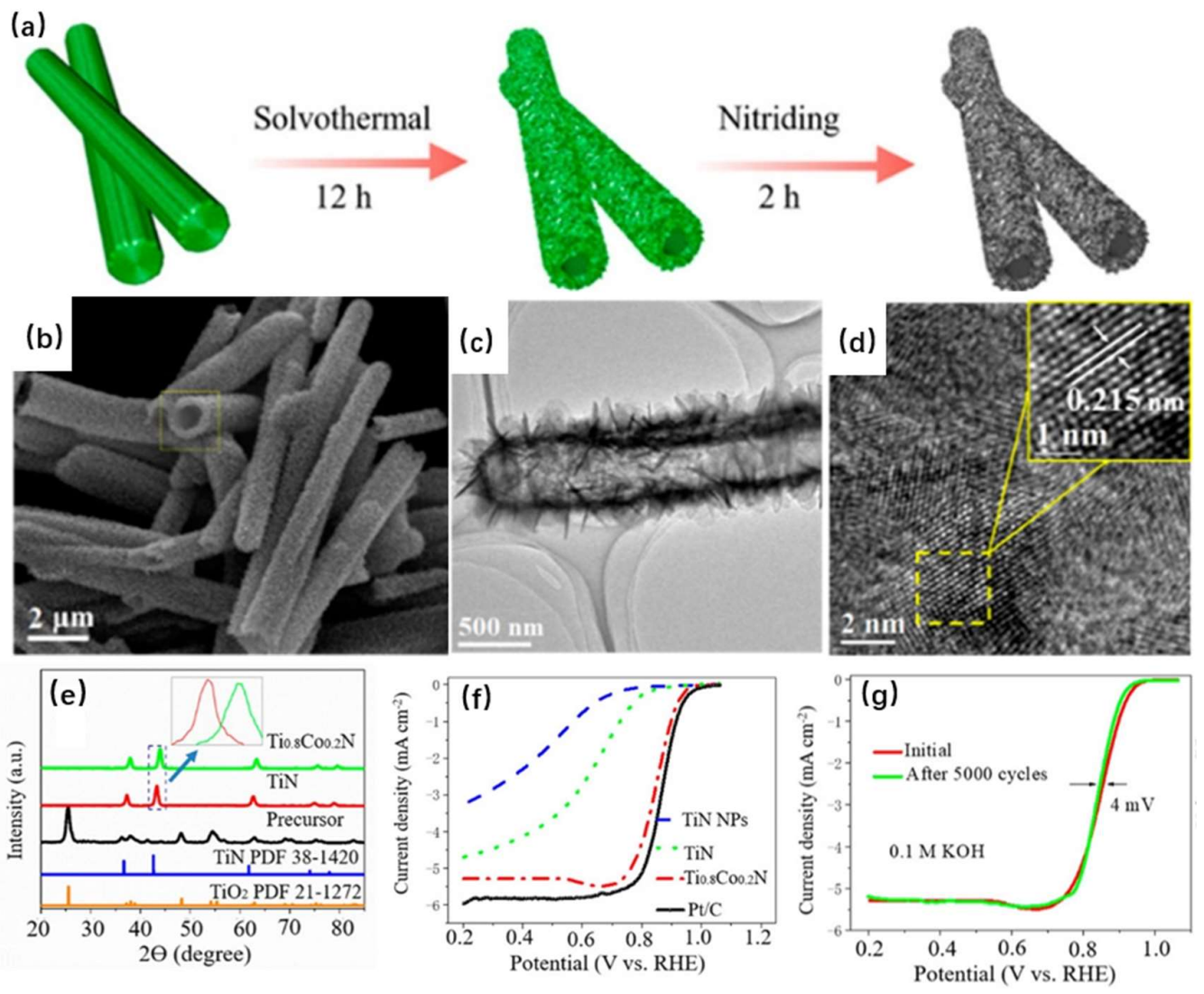

Figure 4. (a) Schematic of the formation of titanium nitrides assemblies; (b) SEM image of Ti0.8Co0.2N assemblies; (c-d) TEM image of Ti0.8 $\mathrm{Co}_{2} \mathrm{~N}$ assemblies; (e)XRD pattern of $\mathrm{TiO}_{2}$, TiN and Ti0.8 $\mathrm{Co}_{2.2} \mathrm{~N}$ assemblies; (f) LSV curves of different electrocatalysts in $0.1 \mathrm{M} \mathrm{KOH}$ electrolyte; (g) potential cycling performance of Ti $0.8 \mathrm{Co} 0.2 \mathrm{~N}$ assemblies. Redrawn with permission of ref.76. Copyright 2018 American Chemical Society.

Different from Tian and co-workers who prepared TMNs electrocatalysts with Co doping on TiN, Li et al.[77] synthesized $\mathrm{Ti}_{0.95} \mathrm{Fe} 0.05 \mathrm{~N}$ support with large specific surface area and high conductivity with hydrothermal method followed by post-nitriding treatment. According to the electrochemical data, $\mathrm{Pt} / \mathrm{Ti} 0.95 \mathrm{Fe} 0.05 \mathrm{~N}$ displayed higher activity and stability than that of $\mathrm{Pt} / \mathrm{C}$. In other words, it was obvious that the ECSA of $\mathrm{Pt} / \mathrm{C}$ and Pt/Tio. ${ }_{95} \mathrm{Fe}_{0.05} \mathrm{~N}$ NTs was decreased by $29 \%$ and $7 \%$ after 1000 cycles and 5000 cycles, respectively, and it diminished $90 \%$ and $30 \%$. Furthermore, introducing Fe into TiN NTs enhanced the synergy between metals, which resulted in an enhanced activity of the $\mathrm{Pt} / \mathrm{Ti} 0.95 \mathrm{Fe} 0.05 \mathrm{~N}$ NTs electrocatalyst.

In addition, Varga et al.[78] prepared the nitrogen-doped graphene electrocatalyst decorated with $\mathrm{FeN}$ and $\mathrm{Fe}_{2} \mathrm{~N}$ using the freeze-dried mixture of graphene oxide and iron salt as raw material. According to the report, the electrocatalyst with the iron content of 
$20 \mathrm{wt} . \%$ achieved the highest current density $\left(3.65 \mathrm{~mA} \mathrm{~cm}^{-2}\right)$, which was better than that of the pristine iron nitride and the undecorated nitrogen-doped graphene. Moreover, the electrocatalysts showed improved methanol tolerance compared with the Pt-based electrocatalyst.

In general, it can be seen from these results that TMNs are a promising to improve the ORR electrocatalyst, especially in an alkaline environment. However, the poor performance of TMNs in acidic medium is also an urgent problem to be solved.

\subsection{Transition metal nitrides as OER electrocatalyst}

There is no doubt that the noble metal ( $\mathrm{Ir}$ and $\mathrm{Ru}$ ) based materials perform excellently in OER. However, the relative scarcity and high cost make their application in this field unsustainable. Therefore, it is important to search for new OER electrocatalytic materials with lower overpotential, superior stability, and lower cost. In recent years, TMNs have attracted a great deal of attention based on their electronic structure similar to that of the precious metals.[22, 23, 79, 80]

\subsubsection{Unary TMN}

The Co-based nitride electrocatalyst exhibits strong electron donating ability and high durability due to the change of the $\mathrm{M}-\mathrm{N}$ bond as well as state density of the metal dband. Chen et al.[81] prepared $\mathrm{C}_{4} \mathrm{~N}$ porous nanowire based on carbon cloth, and the electrocatalyst showed superior activity for OER with $10 \mathrm{~mA} \mathrm{~cm}^{-2}$ at an overpotential of 257 $\mathrm{mV}$, which benefited from the synergy effect of metallic property, 1D porous nanowire arrays, and unique 3D electrode conFigureuration. Later, Zhang et al.[82] proposed a new method to prepare cobalt nitride nanowires through $\mathrm{N}_{2}$ radio-frequency plasma treatment. In this way, it took only 1 min to prepare cobalt nitride.

In addition to cobalt-based TMNs electrocatalysts, nickel-based and iron-based TMNs electrocatalysts are also used in OER. $\mathrm{Ni}_{3} \mathrm{~N}$ nanosheets as OER electrocatalyst was first studied by $\mathrm{Xu}$ and co-workers.[83]. The $\mathrm{Ni}_{3} \mathrm{~N}$ nanosheets performed well in OER with an overpotential of $350 \mathrm{mV}$ and Tafel slope of $45 \mathrm{mV} / \mathrm{dec}$ for abundant active sites as well as favorable conductivity. Surface plasmon resonance (SPR) was a recognized mechanism to enhance the activity of OER, Zeng et al.[84] developed a cation exchange strategy to prepare $\mathrm{Fe}_{2} \mathrm{~N}$ nanoparticles embedded in mesoporous $\mathrm{TiO}_{x} \mathrm{~N}_{\mathrm{y}}$ nanoshells which could be used as a plasmonic material to induce hot electrons and possess high porosity and electrical conductivity. The $\mathrm{Fe}_{2} \mathrm{~N}$ nanoparticles served as an efficient OER electrocatalyst in alkaline medium with an extremely small overpotential of $270 \mathrm{mV}$ at the current density of $10 \mathrm{~mA} \mathrm{~cm}^{-2}$.

\subsubsection{Multivariate TMNs}

To improve the OER activity of TMNs, many scholars try to introduce heteroatoms into unary TMNs to change the electronic structure, optimize the coordination of the active metal center environment, and improve the intermediate adsorption as well as desorption on the interface. 


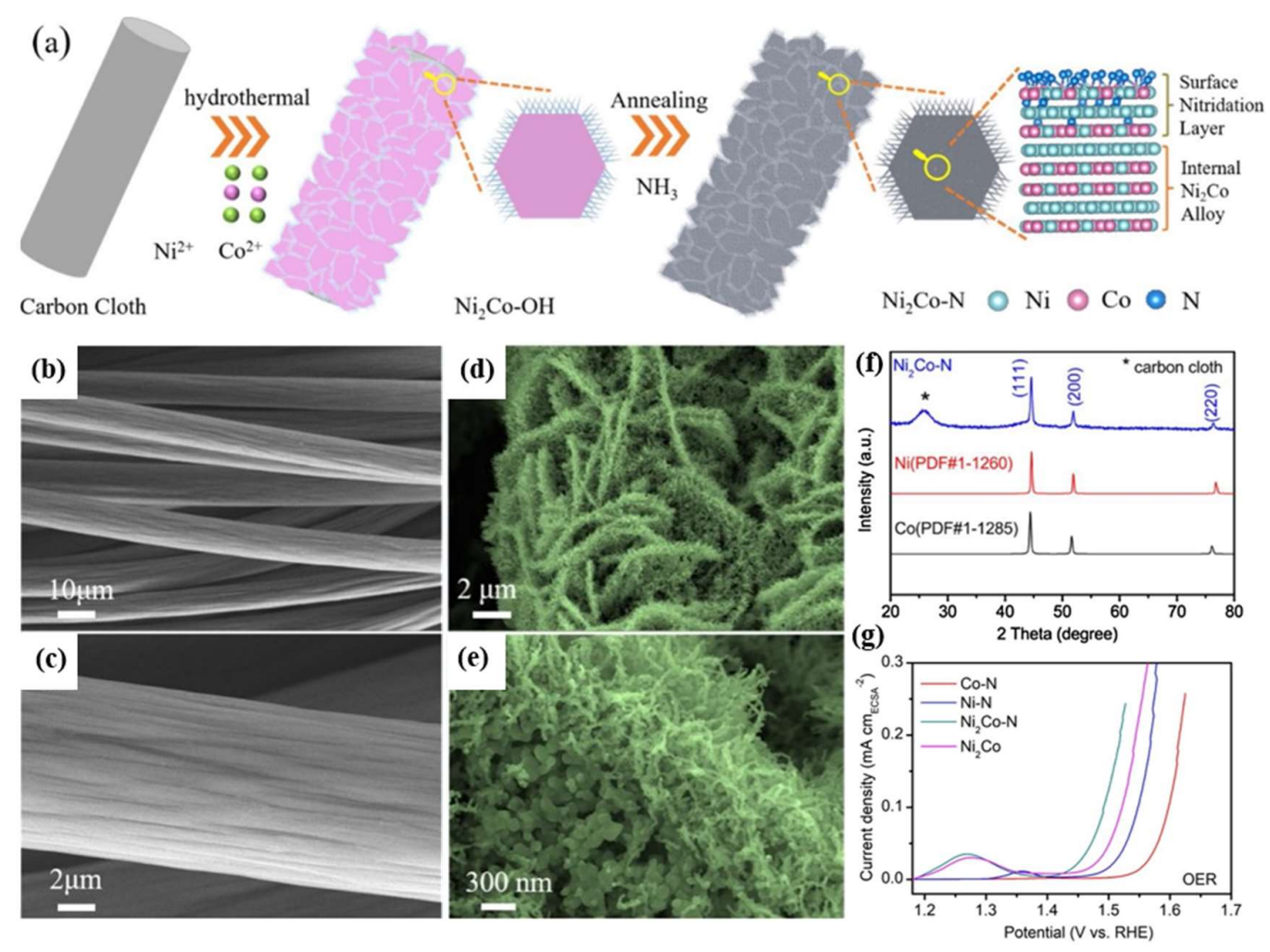

Figure. 5 (a) Schematic illustration of the formation of $\mathrm{Ni}_{2} \mathrm{Co}-\mathrm{N}$ nanocactoids grown on carbon cloth; SEM images of $(b, c)$ bare carbon cloth; $(d, e) \mathrm{Ni}_{2} \mathrm{Co}-\mathrm{N}$; (f) XRD pattern of $\mathrm{Ni}_{2} \mathrm{Co}-\mathrm{N}$; (g) LSV curves of different electrocatalysts in $0.1 \mathrm{M} \mathrm{KOH}$ electrolyte. Redrawn with permission of ref.86. Copyright 2020 Elsevier.

Wang et al.[85] grew nickel-cobalt nitride nanosheets on macroporous Ni foam (NF) by electrodeposition. The obtained $\mathrm{NiCO}_{2} \mathrm{~N}-\mathrm{NF}$ electrocatalyst achieved good stability and high activity for OER with overpotential of $290 \mathrm{mV}$ at $10 \mathrm{~mA} \mathrm{~cm}{ }^{-2}$ due to its 3D interconnected porous structure and the synergistic effect of bimetallic active sites. Gao et al.[86] also studied the synergistic effect of nickel-cobalt and a surface nitridation strategy. They synthesized nickel-cobalt nitride $\left(\mathrm{Ni}_{2} \mathrm{Co}-\mathrm{N}\right)$ nanocactoids on carbon cloth that exhibited a remarkable activity with an overpotential of $214 \mathrm{mV}$ and Tafel slope of $53 \mathrm{mV} \mathrm{dec}-1$ in alkaline media lower than those of $\mathrm{IrO}_{2}$. (Figure.5a-g). Li et al.[87] offered a facile approach to synthesize holey cobalt-iron nitride nanosheet based on Ni foam substrate. The obtained $\mathrm{CoFeN}_{\mathrm{x}} \mathrm{HNAs} / \mathrm{NF}$ served as attractive OER electrocatalyst with a large ECSA, low charge transfer resistance, and rapid gas diffusion. Besides, the electrocatalyst showed a low overpotential of $260 \mathrm{mV}$. Liu et al.[88] studied the effect of molar ratio of iron atom and cobalt atom on Fe-CoN electrocatalyst. According to this report, $\mathrm{CoFe}(3: 1)-\mathrm{N}$ showed a remarkable activity for OER with an overpotential of $200 \mathrm{mV}$ and excellent durability. Sun et al.[89] took advantage of the synergistic effect of $\mathrm{Co} 4 \mathrm{~N}-\mathrm{CeO}_{2}$ to prepare $\mathrm{Co} 4 \mathrm{~N}-\mathrm{CeO}_{2}$ hybrid nanosheet array grown on a graphite plate $\left(\mathrm{Co}_{4} \mathrm{~N}-\mathrm{CeO}_{2} / \mathrm{GP}\right)$ by anion intercalation enhanced electrodeposition route and subsequent nitridation (Figure. 6a-c). The treatment of $\mathrm{CeO}_{2}$ coupling $\mathrm{CO}_{4} \mathrm{~N}$ porous nanosheet significantly enhanced the OER activity, which was evidenced by a low overpotential of $239 \mathrm{mV}$ to reach a current density of $10 \mathrm{~mA} \mathrm{~cm}^{-2}$ and long-term durability at a large current density of $500 \mathrm{~mA} \mathrm{~cm}^{-2}$ for $50 \mathrm{~h}$ (Figure. 6d, e). 

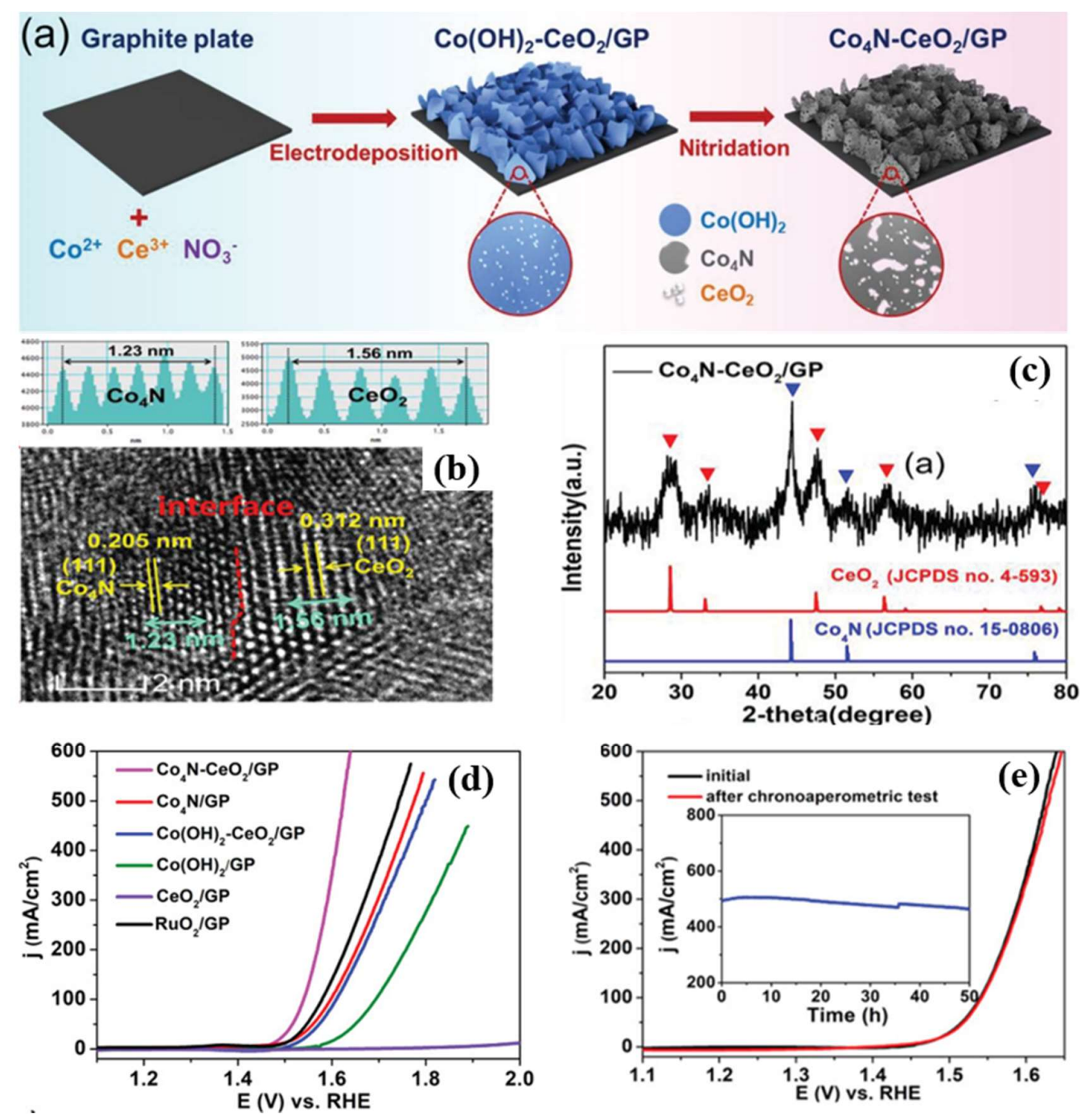

Figure. 6 (a) Schematic of the formation of the $\mathrm{CO}_{4} \mathrm{~N}-\mathrm{CeO}_{2} / \mathrm{GP}$; (b) HRTEM image of $\mathrm{CeO}_{2}$ and $\mathrm{CO}_{4} \mathrm{~N}$; (c) XRD pattern of $\mathrm{Co}_{4} \mathrm{~N}-\mathrm{CeO}_{2} / \mathrm{GP}$; (d) LSV curves of different electrocatalysts in $0.1 \mathrm{M} \mathrm{KOH}$ electrolyte; (e) potential cycling performance of $\mathrm{Co}_{4} \mathrm{~N}-\mathrm{CeO}_{2} / \mathrm{GP}$. Redrawn with permission of ref.89. Copyright 2020 Wiley-VCH Verlag.

For nickel-iron bimetallic TMNs electrocatalyst, Kwag et al.[90] synthesized two-dimensional and nanocrystalline $\mathrm{Fe}_{2} \mathrm{Ni}_{2} \mathrm{~N} / \mathrm{rGO}$ nanohybrid sheets. The electrocatalyst showed superior activity with overpotential of $290 \mathrm{mV}$ at $10 \mathrm{~mA} \mathrm{~cm} \mathrm{~cm}^{-2}$ and robust longterm stability for $24 \mathrm{~h}$, due to the synergistic effect between nanocrystalline $\mathrm{Fe}_{2} \mathrm{Ni}_{2} \mathrm{~N}$ and graphene nanosheets as well as its unique nanoarchitectures. Liang et al.[91] prepared $\mathrm{FeNi}_{3} \mathrm{~N}-\mathrm{Ni}_{3} \mathrm{~S}_{2}$ electrocatalyst by hydrothermal and nitridation process (Figure.7a,b), and the obtained electrocatalyst reveals an extremely brilliant OER properties and long-term stability with a overpotential of $230 \mathrm{mV}$ and a small Tafel slope of $38 \mathrm{mV} \mathrm{dec}^{-1}$ (Figure.7ce). The high ECSA and the electron effect between $\mathrm{FeNi}_{3} \mathrm{~N}$ and $\mathrm{Ni}_{3} \mathrm{~S}_{2}$ were also explained, which reduced the activation energy of OER, and thus enhanced the intrinsic activity of the electrocatalyst. To further prove that the Fe doping modified the electronic structure of $\mathrm{Ni}_{3} \mathrm{~N}$, and improved the redox activity of the electrocatalyst surface, thereby significantly improving the electrocatalytic OER performance. Li et al.[92] prepared transition metal nitride, $\mathrm{Ni} 3 \mathrm{FeN}$, which grew on a 3D network-like support of the strutted graphene foam (NizFeN/SG). The electrocatalyst showed enhanced OER activity, as evidenced by a 
low overpotential of $226 \mathrm{mV}$ at $10 \mathrm{~mA} \mathrm{~cm}^{-2}$. It also indicated that the 3D structure increased the ECSA and promoted active site dispersion, which helped the diffusion of the reactants and accelerated the electrocatalytic OER process. Similarly, Wang et al.[93] compounded a $\mathrm{NiFeOOH} / \mathrm{Ni} 3 \mathrm{FeN} / \mathrm{Ni}$ heterojunction and stressed the importance of heterojunction in improving OER activity. They found the as-obtained electrocatalyst showed attractive performance for $\mathrm{OER}$, and $\mathrm{Ni} 3 \mathrm{FeN} / \mathrm{Ni}$ was largely beneficial for charge transfer, such electrocatalyst only required overpotential of $200 \mathrm{mV}$ to actuate $10 \mathrm{~mA} \mathrm{~cm}{ }^{-2}$, which was superior to most recently reported electrocatalysts and commercial $\mathrm{RuO}_{2}$.

(a)

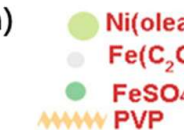

)

FesO

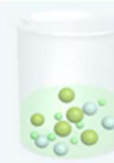

(c)

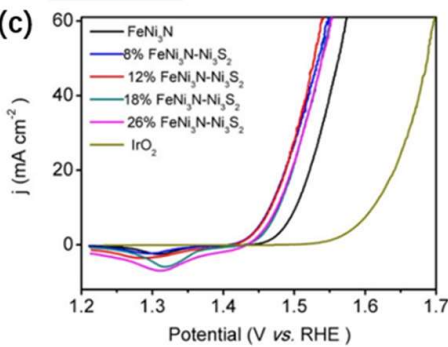

Hydrothermal

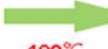

$180^{\circ} \mathrm{C}$

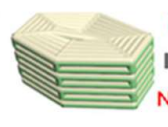
Nitridation $\mathrm{NH}_{3} 350-500^{\circ}$

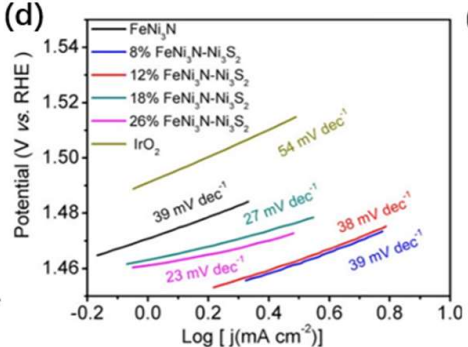

(b)

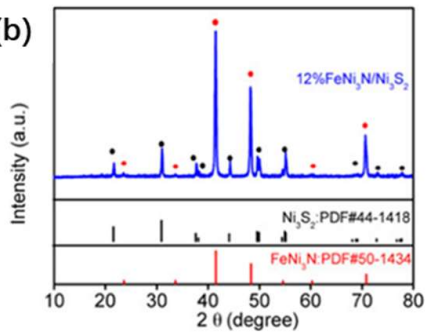

(e)

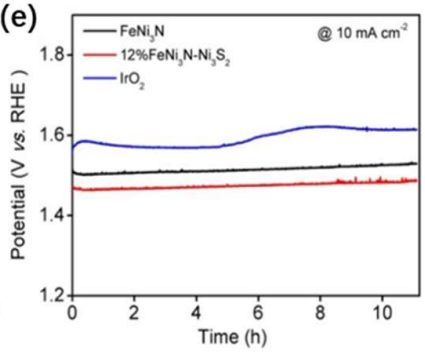

Figure. 7 (a) Schematic illustration of the formation of $\mathrm{FeNi}_{3} \mathrm{~N}-\mathrm{Ni}_{3} \mathrm{~S}_{2}$ samples; (b) XRD pattern of $\mathrm{FeNi}_{3} \mathrm{~N}-\mathrm{Ni}_{3} \mathrm{~S}_{2}$; (c) LSV curves of different electrocatalysts in $0.1 \mathrm{M} \mathrm{KOH}$ electrolyte; (d) Tafel plots of different electrocatalysts; (e) potential cycling performance of $\mathrm{FeNi}_{3} \mathrm{~N}-\mathrm{Ni}_{3} \mathrm{~S}_{2}, \mathrm{FeNi}_{3} \mathrm{~N}$, and $\mathrm{IrO}_{2}$. Redrawn with permission of ref.91. Copyright 2020 American Chemical Society.

Jia et al.[94] synthesized Ni-doped molybdenum nitride nanorods, which not only performed a remarkable small overpotential of $218 \mathrm{mV}$ but also maintained long-term stability for 110 hours. It also indicated that TMNs in combination with multiple active components could produce heterostructure that enhanced the electrocatalyst activity. 
Table 1 Summary of TMNs activity as OER electrocatalysts.

\begin{tabular}{|c|c|c|c|c|}
\hline Electrocatalysts & Electrolyte & $\begin{array}{c}\mathrm{E}_{\mathrm{i}=10} \\
\text { [V vs. } \mathrm{RHE}]\end{array}$ & $\begin{array}{l}\text { Tafet slope } \\
{\left[\mathrm{mV} \mathrm{dec}^{-1}\right]}\end{array}$ & Ref. \\
\hline $\mathrm{Co} 4 \mathrm{~N}$ & $1 \mathrm{M} \mathrm{KOH}$ & 1.49 & 44 & [81] \\
\hline $\mathrm{CoN}$ & $1 \mathrm{M} \mathrm{KOH}$ & 1.52 & 70 & [82] \\
\hline $\mathrm{Ni}_{3} \mathrm{~N}$ & $1 \mathrm{M} \mathrm{KOH}$ & 1.58 & 45 & [83] \\
\hline $\mathrm{NiCO}_{2} \mathrm{~N} / \mathrm{NF}$ & $1 \mathrm{M} \mathrm{KOH}$ & 1.52 & 65 & [85] \\
\hline $\mathrm{Ni}_{2} \mathrm{Co}-\mathrm{N}$ & $1 \mathrm{M} \mathrm{KOH}$ & 1.44 & 53 & [86] \\
\hline $\mathrm{CoFeN}_{x} \mathrm{HNAs} / \mathrm{NF}$ & $1 \mathrm{M} \mathrm{KOH}$ & 1.49 & 57 & [87] \\
\hline $\mathrm{CoFe}_{(3: 1)-\mathrm{N}}$ & $1 \mathrm{M} \mathrm{KOH}$ & 1.43 & 42 & [88] \\
\hline $\mathrm{CO}_{4} \mathrm{~N}-\mathrm{CeO}_{2} / \mathrm{GP}$ & $1 \mathrm{M} \mathrm{KOH}$ & 1.47 & 46 & [89] \\
\hline $\mathrm{Fe}_{2} \mathrm{Ni}_{2} \mathrm{~N} / \mathrm{rGO}$ & $1 \mathrm{M} \mathrm{KOH}$ & 1.52 & 49 & {$[90]$} \\
\hline $\mathrm{FeNi}_{3} \mathrm{~N}-\mathrm{Ni}_{3} \mathrm{~S}_{2}$ & $1 \mathrm{M} \mathrm{KOH}$ & 1.46 & 38 & [91] \\
\hline $\mathrm{Ni}_{3} \mathrm{FeN} / \mathrm{SG}$ & $1 \mathrm{M} \mathrm{KOH}$ & 1.46 & 43 & [92] \\
\hline $\mathrm{NiFeOOH} / \mathrm{Ni} 3 \mathrm{FeN} / \mathrm{Ni}$ & $1 \mathrm{M} \mathrm{KOH}$ & 1.43 & 36 & [43] \\
\hline Nifoam@Ni-Nio.2Mo0.8N & $1 \mathrm{M} \mathrm{KOH}$ & 1.45 & 39 & [93] \\
\hline
\end{tabular}

\subsection{Transition metal nitrides electrocatalyst for ORREOER}

So far, Ir-based electrocatalysts are considered to be the best OER electrocatalysts. In the meantime, Pt-based electrocatalysts are the best choices for ORR. However, pure Irbased or Pt-based materials are too expensive, and not sufficiently active for bifunctional OER and ORR. Hence TMNs serving as highly active and long-term stable bifunctional electrocatalysts have been widely investigated.[95, 96]

A novel bifunctional electrocatalyst (Ni3FeN/NRGO) was prepared by Fan et al.[97] , which substituted for the commercial noble-metal electrocatalysts. The NRGO not only dispersed the $\mathrm{Ni}_{3} \mathrm{FeN}$ nanoplates, but also provided a conductive framework for the high retention of the ECSA and improvement of the synergistic effect in the OER and ORR processes. By coupling the theoretical and experimental approaches, $\mathrm{Ni} 3 \mathrm{FeN} / \mathrm{NRGO}$ was confirmed to show high performance in both OER and ORR with the lowest onset overpotential of $150 \mathrm{mV}$ for OER and the onset potential of $0.9 \mathrm{~V}$ for ORR. In addition, Wang et al.[98] delivered a novel bifunctional $\mathrm{Ni} 3 \mathrm{FeN} / \mathrm{Co}, \mathrm{N}-\mathrm{CNF}$ electrocatalyst driving both OER and ORR. Because of $\mathrm{Co}, \mathrm{N}-\mathrm{CNF}$ as the support of the electrocatalyst, the $\mathrm{Ni}_{3} \mathrm{FeN}$ nanoparticles achieved highly dispersed. At the same time, as a result of the synergistic effect of $\mathrm{Ni} 3 \mathrm{FeN} / \mathrm{Co}$ and $\mathrm{N}-\mathrm{CNF}$, the as-prepared electrocatalyst had better OER and ORR activities than noble metal electrocatalysts with the low overpotential of $0.27 \mathrm{~V}$ for OER and $\mathrm{E}_{1 / 2}$ of $0.81 \mathrm{~V}$ for ORR. Zhang et al.[99] also reported ultra-small nanoparticles $\left(\mathrm{Fe}_{2} \mathrm{~N}\right)$ grown on CNTs. Compared with the pure $\mathrm{Fe}_{2} \mathrm{~N}$ nanoparticles, the $\mathrm{Fe}_{2} \mathrm{~N}$ nanoparticles in $\mathrm{Fe}_{2} \mathrm{~N}$-CNTs was extremely smaller $(5 \mathrm{~nm})$. Thus, The $\mathrm{E}_{1 / 2}$ of $\mathrm{Fe}_{2} \mathrm{~N}-\mathrm{CNTs}$ for ORR was $0.71 \mathrm{~V}$, and the overpotential for OER was $240 \mathrm{mV}$. This work might bring us a novel, environmentally friendly approach for the preparation of ultra-small TMNs. To further improve the stability of nickel-iron nitride electrocatalyst, Fu et al.[100] prepared mesoporous nickel-iron nitride bifunctional electrocatalyst without carbon as support (Figure.8a). The $\mathrm{Ni}_{3} \mathrm{FeN}$ electrocatalyst was microsphere with hierarchically porous structure, which provided generous interparticle void space and high specific surface area (Figure.8b-g). In this manner, it showed excellent ORR activity with $\mathrm{E}_{1 / 2}$ of $0.78 \mathrm{~V}$ and OER activity with a low overpotential of $355 \mathrm{mV}$ at $10 \mathrm{~mA} \mathrm{~cm}^{-2}$ in alkaline solution (Figure.8h,i). A trimetallic (NiFeMn) nitride electrocatalyst was produced by $\mathrm{Wu}$ et al.[101] in a molecular sheet form, which was stabilized by Ti metal on titanium carbide $\left(\mathrm{Ti}_{3} \mathrm{C}_{2}\right)$ sheets. Intimate contact 
between the two sheets produced a strong force at the interface, thus effectively avoiding the accumulation of a nitride sheet. This work unlocked a high electrocatalytic performance of bifunctional trimetallic nitride electrocatalyst, and provided a new way for the application of two-dimensional sheets in flexible and wearable devices. Different from the above, Cui et al.[102] prepared $\mathrm{Fe}_{3} \mathrm{Pt}$ electrocatalyst with porous nickel-iron nitride as the support. On the one hand, unlike the widely studied Pt-M disordered alloys, ordered $\mathrm{Fe}_{3} \mathrm{Pt}$ intermetallic nanoalloy had definite composition and structure, which was beneficial for the formation of highly dispersed active sites.[103] On the other hand, $\mathrm{Ni}_{3} \mathrm{FeN}$ support showed brilliant chemical stability and high conductivity. Therefore, $\mathrm{Fe}_{3} \mathrm{Pt} / \mathrm{Ni}_{3} \mathrm{FeN}$ electrocatalyst released excellent electrocatalytic activity for OER and ORR at the same time, and achieved a long-term cycling performance of over $480 \mathrm{~h}$ at $10 \mathrm{~mA}$ $\mathrm{cm}^{-2}$ in $\mathrm{Zn}$-air batteries.

(a)

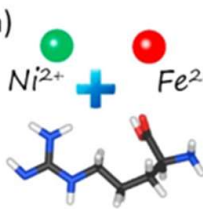

Arginine

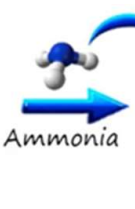

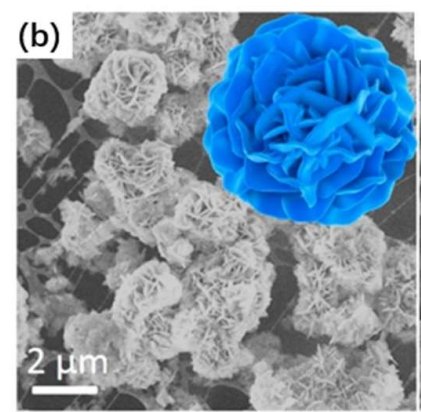

(e)
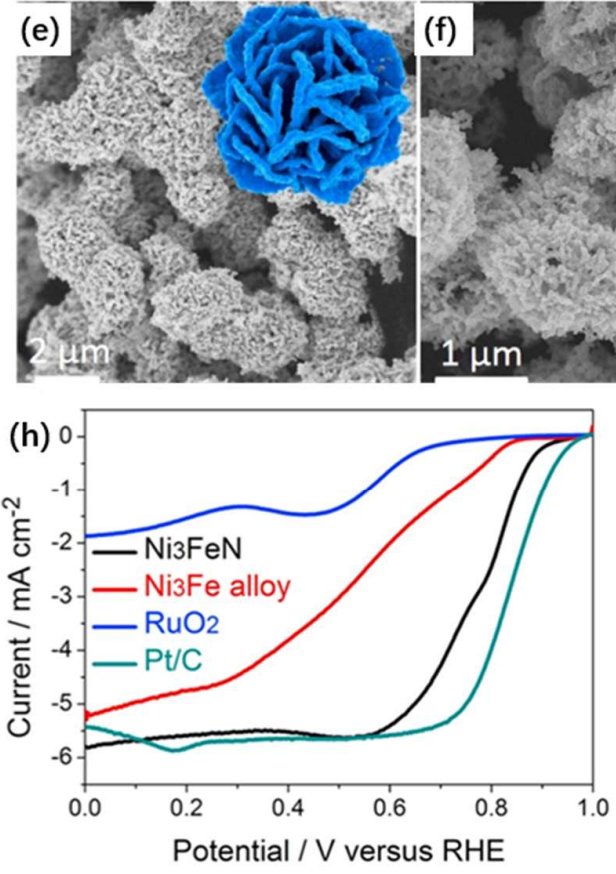

(f)

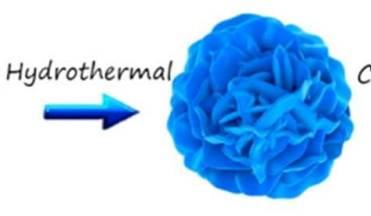

Porous NiFe LDH microspheres

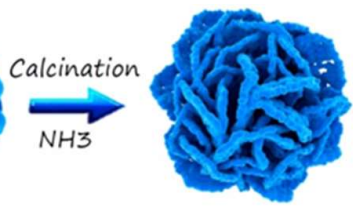

Porous NizFeN microspheres
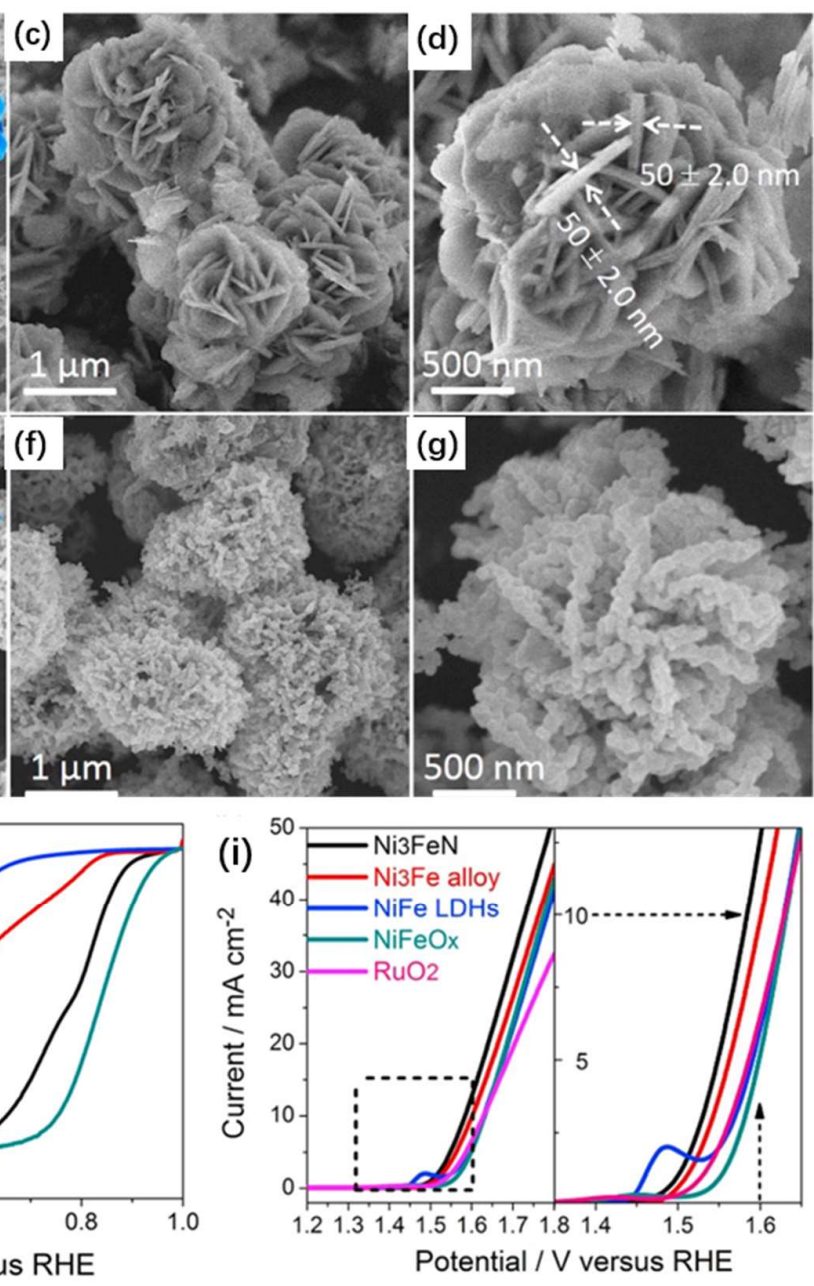

Figure. 8 (a) Schematic of the formation of the porous Ni3FeN hierarchical microspheres; (b-d) SEM images of the NiFe LDH hierarchical microspheres; (e-g) SEM images of the porous NizFeN hierarchical microspheres; (h) ORR LSV curves in 0.1 M KOH electrolyte; (i) OER LSV curves in $0.1 \mathrm{M}$ $\mathrm{KOH}$ electrolyte. Redrawn with permission of ref.99. Copyright 2017 Elsevier. 
In addition to nickel-iron nitride, Davari et al.[104] produced a mixture of two MnN phases ( $\mathrm{Mn}_{4} \mathrm{~N}$ and $\left.\mathrm{Mn}_{6} \mathrm{~N}_{2.58}\right)$ as bifunctional electrocatalysts for rechargeable Zn-air batteries. Although the obtained $\mathrm{MnN}$ particles were irregular in shape with the size of 100 $\mu \mathrm{m}$, the high covalent nature of the $\mathrm{Mn}-\mathrm{N}$ bond provided a greater driving force for the electrocatalytic reaction,[105] thus making the electrocatalyst show superior bifunctional activity. At the same time, it exhibited good ORR and OER stability for at least 1500 cycles in $0.1 \mathrm{M} \mathrm{KOH}$.

(a)
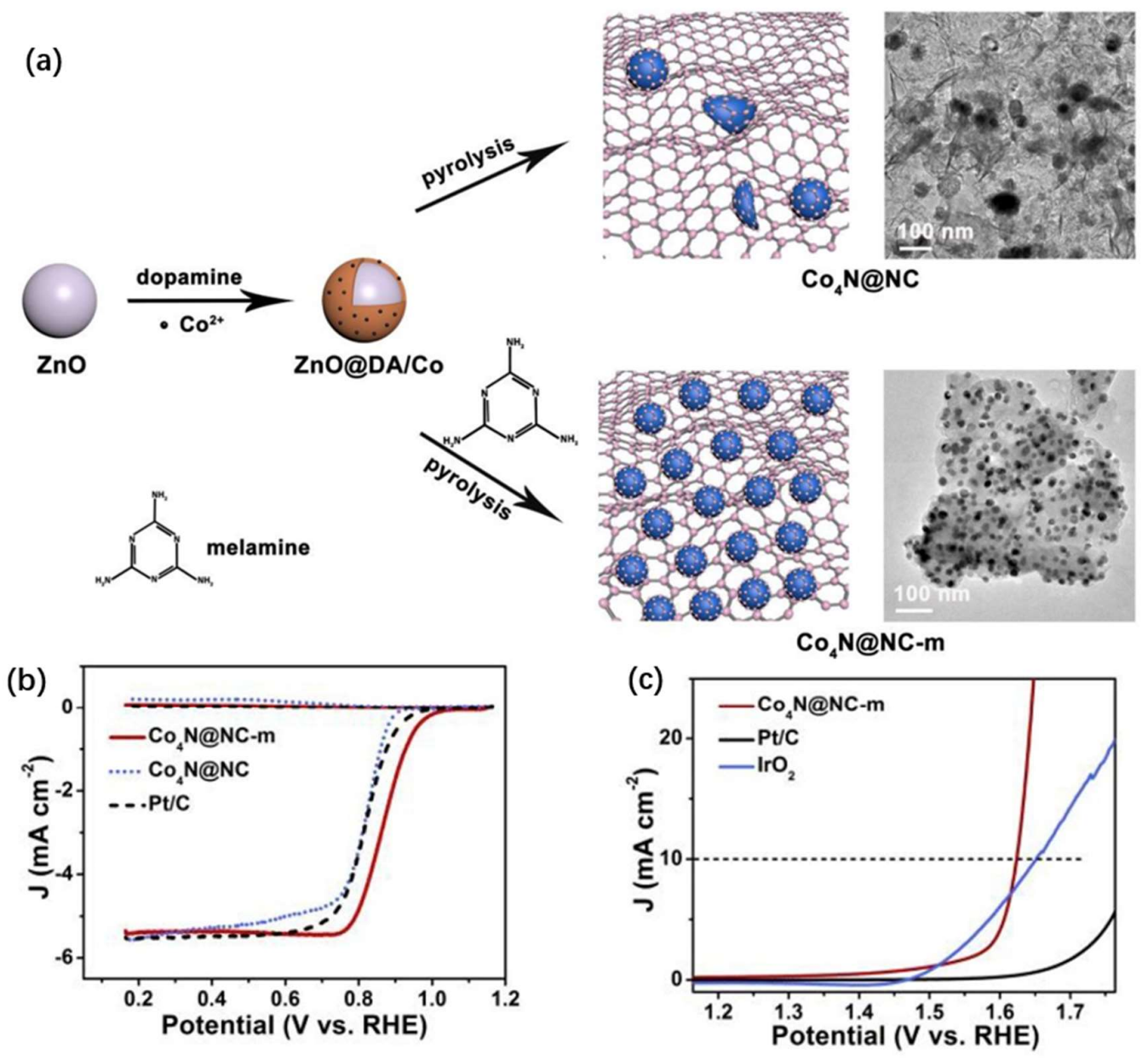

Figure. 9 (a) Schematic of the formation of $\mathrm{Co} 4 \mathrm{~N} @ \mathrm{NC}-\mathrm{m}$ and Co4N@NC; (b) ORR LSV curves in 0.10 $\mathrm{M} \mathrm{KOH}$ electrolyte; (c)OER LSV curves in $0.1 \mathrm{M} \mathrm{KOH}$ electrolyte. Redrawn with permission of ref.105. Copyright 2019 Elsevier.

Chen et al.[106] obtained Co4N@N-doped carbon with the assistance of melamine. Besides, they cleverly added melamine to help increase conductivity, the amount of nitrogen doping, and ECSA of the electrocatalyst, and regulate the size and distribution of $\mathrm{Co}_{4} \mathrm{~N}$ nanocrystals (Figure.9a). Therefore, $\mathrm{Co} 4 \mathrm{~N} @ \mathrm{NC}-\mathrm{m}$ served as a high activity and longterm stability electrocatalyst for both ORR/OER and air cathode of rechargeable Zn-air batteries. Besides, their work provided an effective approach to synthesize non-noble metal electrocatalysts with controllable morphology (Figure.9b, c). Guan et al.[107] studied the cobalt nitride nanoparticles supported on nitrogen-doped reduced graphene oxide sheet (O-S-Co5.47N@N-RGO). Such flexible material showed marvelous electrocatalytic activity towards both OER and ORR with low overpotentials $380 \mathrm{mV}$ at $10 \mathrm{~mA} \mathrm{~cm}{ }^{-2}$ current density and $\mathrm{E}_{1 / 2}$ of $0.82 \mathrm{~V}$ in $1 \mathrm{M} \mathrm{KOH}$ solution. It was believed that the Co- $\mathrm{N}_{4}$ sites in the RGO sheet and the Co sites on the surface of O-S-Co5.47 N crystal were the active sites for ORR and OER, respectively. Gao et al.[108] developed cobalt-iron bimetallic nitrides with 
N-doped multi-walled carbon nanotubes (Co-Fe-N@MWCNT). It was worth noting that MWCNTs acted as a bridge to connect nanoparticles to optimize the conductivity of the electrocatalyst, while regulating the uniform dispersion of nanoparticles to increase ECSA.[109] In addition, there was a strong interaction between iron and cobalt, and iron could effectively regulate the conversion of cobalt from cobalt (III) to cobalt (IV).[110] Thus, Co-Fe-N@MWCNT performed well for both OER and ORR.

Table 2 Summary of TMNs activity as OER\&ORR electrocatalysts (the voltage gap: $\Delta \mathrm{E}=$ $\left.\mathrm{E}_{\mathrm{i}=10}-\mathrm{E}_{1 / 2}\right)$

\begin{tabular}{cccccc}
\hline Electrocatalysts & Electrolyte & $\begin{array}{c}\mathrm{E}_{1 / 2} \\
\text { for ORR } \\
\text { [V vs. RHE] }\end{array}$ & $\begin{array}{c}\mathrm{E}_{\mathrm{i}=10} \\
\text { for OER } \\
\text { [V vs. RHE] }\end{array}$ & $\begin{array}{c}\Delta \mathbf{E} \\
\text { [V] }\end{array}$ & Ref. \\
\hline $\mathrm{Ni} 3 \mathrm{FeN} / \mathrm{NRGO}$ & $0.1 \mathrm{M} \mathrm{KOH}$ & 0.72 & 1.38 & 0.77 & {$[96]$} \\
$\mathrm{Ni}$ FeN/Co,N-CNF & $0.1 \mathrm{M} \mathrm{KOH}$ & 0.81 & 1.50 & 0.69 & {$[97]$} \\
$\mathrm{Fe} 2 \mathrm{~N} / \mathrm{N}-\mathrm{CNTs}$ & $0.1 \mathrm{M} \mathrm{KOH}$ & 0.71 & 1.66 & 0.95 & {$[98]$} \\
$\mathrm{Ni} 3 \mathrm{FeN}$ & $0.1 \mathrm{M} \mathrm{KOH}$ & 0.78 & 1.58 & 0.7 & {$[99]$} \\
$\mathrm{NiFeMnN}$ & $0.1 \mathrm{M} \mathrm{KOH}$ & 0.84 & 1.52 & 0.68 & {$[100]$} \\
$\mathrm{Fe} 3 \mathrm{Pt} / \mathrm{Ni} 3 \mathrm{FeN}$ & $0.1 \mathrm{M} \mathrm{KOH}$ & 0.93 & 1.60 & 0.72 & {$[101]$} \\
$\mathrm{Co} 4 \mathrm{~N} @ \mathrm{NC}-\mathrm{m}$ & $0.1 \mathrm{M} \mathrm{KOH}$ & 0.87 & 1.63 & 0.81 & {$[105]$} \\
$\mathrm{Co} .47 \mathrm{~N}$ & $0.1 \mathrm{M} \mathrm{KOH}$ & 0.82 & 1.61 & 0.80 & {$[106]$} \\
$\mathrm{Co}-\mathrm{Fe}-\mathrm{N} @ \mathrm{MWCNT}$ & $0.1 \mathrm{M} \mathrm{KOH}$ & 0.92 & 1.52 & 0.72 & {$[107]$} \\
\hline
\end{tabular}

3.4 Design principles of TMNs electrocatalysts for oriented applications

TMNs play a key role in electrocatalytic application especially in OER and ORR. The oxygen-involved reactions require extremely abundant accessible electrocatalytic sites due to its slow kinetics. Thus the reasonably designing TMNs is an effective approach to improve the performance for electrocatalytic application.

In the aspect of doping agents, the electrocatalyst is desired to adjust the electronic structure to improve the ability of donating electrons to adsorbed oxygen. Furthermore, the doping agents show great influence on the microstructures of electrocatalysts. With the defects producing, active centers are formed, which is beneficial to capture electrons and speed up mass electron transport.

On the other hand, the electrocatalyst is expected to possess a large number of exposed active sites since the electrocatalytic reaction takes place on the electrochemical surface of the electrocatalyst. Hence nanostructure with high specific surface area such as nanoflowers, hierarchically macropores and mesopores is required to take full advantage of exposed active sites. The strong synergy between the intrinsic activity and nanostructures is also demanded to achieve the improvement of electrocatalytic performance.

\section{Conclusions and perspectives}

In this review, we summarized the recent advances in the synthesis and application of transition metal nitrides for oxygen reduction reaction and oxygen evolution reaction. Selecting different transition metal ions ( $\mathrm{Ti}, \mathrm{Ni}, \mathrm{Fe}, \mathrm{Co}, \mathrm{Mo}$ ) or introducing heteroatoms into the unary transition metal could make the TMNs produce similar properties to noble metal. Similarly, high-efficiency multiscale mass transfer structure was constructed by using TMNs nanowires and mesoporous structure, which had been proved to greatly enhance the electrocatalytic performance of TMNs. To improve the preparation and application of TMNs, the following challenges need to be studied later.

Firstly, the preparation of TMNs electrocatalysts has been restricted to laboratory preparation, which cannot be produced on a large scale due to its complicated preparation 
and high cost. Therefore, simple, low-cost, and environmentally friendly preparation methods should be investigated as a part of the subsequent research.

Secondly, in acidic media or under the conditions with extreme $\mathrm{pH}$ value, the activity of TMNs electrocatalysts will severely reduce due to the dissolution of transition metals, protonation of active sites, and corrosion of conductive substrates. Therefore, TMNs electrocatalysts with robust stability need to be developed.

Thirdly, to further improve the electrocatalytic activity, the electronic structure can be adjusted based on the d-band center theory by doping with metal or non-metal elements, forming a heterostructure, or using a synergistic effect.

Finally, the in-situ techniques like XRD/ND-analysis, TEM, and XPS are used to monitor the changes of TMNs during the preparation process and the electrocatalytic reaction process, which is beneficial for the understanding the principle of TMNs catalysis and provides a theoretical basis for subsequent electrocatalyst research.

Acknowledgments: This work was supported by the National Natural Science Foundation of China (51976143), Na-tional Key Research and Development Program of China (2018YFA0702001), the Key Research and Development Program of Guangdong Province (2019B090909003), and Foshan Xianhu La-boratory of the Advanced Energy Science and Technology Guangdong Laboratory (XHD2020002).

Conflicts of Interest: There are no conflicts to declare.

\section{References}

1. Johnston, B.; Mayo, M. C.; Khare, A. Hydrogen: the energy source for the 21st century. Technovation 2005, 25, 569-585.

2. Dong, S. B.; Hu, L. M.; Li, X. M.; Ouyang, X. D., The Development and Utilization of New Energy. In Natural Resources and Sustainable Development, Pts 1-3, Xu, Q. J.; Ge, H. H.; Zhang, J. X., Eds. Trans Tech Publications Ltd: Stafa-Zurich, 2012; Vol. 361363, pp 1333-1336.

3. Mao, J.; Hong, D.; Ren, R. W.; Li, X. Y. The Effect of Marine Power Generation Technology on the Evolution of Energy Demand for New Energy Vehicles. J. Coast. Res. 2020, 1006-1009.

4. Perry, M. L.; Fuller, T. F. A historical perspective of fuel cell technology in the 20th century. J. Electrochem. Soc. 2002, 149, S59S67.

5. Gu, P.; Xu, Y. X.; Zhao, Y. F.; Liu, W.; Xue, H. G.; Pang, H. Electrocatalysis of Rechargeable Non-Lithium Metal-Air Batteries. Adv. Mater. Interfaces 2017, 4, 9.

6. Meng, Z.; Chen, N.; Cai, S.; Wang, R.; Guo, W.; Tang, H. Co-N-doped hierarchically ordered macro/mesoporous carbon as bifunctional electrocatalyst toward oxygen reduction/evolution reactions. International Journal of Energy Research 2021, 45, 62506261.

7. Ding, L.; Tang, T.; Hu, J. S. Recent Progress in Proton-Exchange Membrane Fuel Cells Based on Metal-Nitrogen-Carbon Catalysts. Acta Phys.-Chim. Sin. 2021, 37, 21.

8. Lu, X. Q.; Qu, Y.; Wang, Y. D.; Qin, C.; Liu, G. A comprehensive review on hybrid power system for PEMFC-HEV: Issues and strategies. Energy Conv. Manag. 2018, 171, 1273-1291.

9. Ijaodola, O.; Ogungbemi, E.; Khatib, F. N.; Wilberforce, T.; Ramadan, M.; El Hassan, Z.; Thompson, J.; Olabi, A. G. Evaluating the Effect of Metal Bipolar Plate Coating on the Performance of Proton Exchange Membrane Fuel Cells. Energies 2018, 11, 28.

10. Wang, C.; Wang, S. B.; Peng, L. F.; Zhang, J. L.; Shao, Z. G.; Huang, J.; Sun, C. W.; Ouyang, M. G.; He, X. M. Recent Progress on the Key Materials and Components for Proton Exchange Membrane Fuel Cells in Vehicle Applications. Energies $2016,9,39$.

11. Feng, Y.; Li, F.; Hu, Z.; Luo, X.; Zhang, L.; Zhou, X.-F.; Wang, H.-T.; Xu, J.-J.; Wang, E. G. Tuning the catalytic property of nitrogen-doped graphene for cathode oxygen reduction reaction. Physical Review B 2012, 85.

12. Nordin, N., Limitations of Commercializing Fuel Cell Technologies. In 10th Asian International Conference on Fluid Machinery, Wahid, M. A.; Sheriff, J. M.; Sidik, N. A. C.; Samion, S., Eds. Amer Inst Physics: Melville, 2010; Vol. 1225, pp 498-506.

13. Cheng, F. Y.; Chen, J. Metal-air batteries: from oxygen reduction electrochemistry to cathode catalysts. Chem. Soc. Rev. 2012, 41, 2172-2192.

14. Laughton, M. A. Fuel cells (Reprinted from Engineering Science and Education Journal). Power Eng. J. 2002, 16, 37-47.

15. Le, T.; Ieee, I., Fuel cells: The epidemic of the future. 2003; p 505-510.

16. Lee, J. S.; Kim, S. T.; Cao, R.; Choi, N. S.; Liu, M.; Lee, K. T.; Cho, J. Metal-Air Batteries with High Energy Density: Li-Air versus Zn-Air. Adv. Energy Mater. 2011, 1, 34-50.

17. Meng, Z.; Cai, S.; Wang, R.; Tang, H.; Song, S.; Tsiakaras, P. Bimetallic-organic framework-derived hierarchically porous Co$\mathrm{Zn}-\mathrm{N}-\mathrm{C}$ as efficient catalyst for acidic oxygen reduction reaction. Applied Catalysis B: Environmental 2019, 244, $120-127$.

18. Zhou, Y.; Guo, W.; Li, T. A review on transition metal nitrides as electrode materials for supercapacitors. Ceram. Int. 2019, 45, 
21062-21076.

19. Ota, K.; Ohgi, Y.; Matsuzawa, K.; Mitsushima, S.; Ishihara, A., Transition Metal Oxide Based Materials for Cathode of Polymer Electrolyte Fuel Cells. In Tutorials on Electrocatalysis in Low Temperature Fuel Cells, Zawodzinski, T.; Mukerjee, S.; Strasser, P., Eds. Electrochemical Soc Inc: Pennington, 2012; Vol. 45, pp 27-33.

20. Zhang, Z.; Zhang, H.; Yao, Y.; Wang, J.; Guo, H.; Deng, Y.; Han, X. Controlled Synthesis and Structure Engineering of Transition Metal-based Nanomaterials for Oxygen and Hydrogen Electrocatalysis in Zinc-Air Battery and Water-Splitting Devices. ChemSusChem 2021, 14, 1-16.

21. Zheng, J.; Zhang, W.; Zhang, J.; Lv, M.; Li, S.; Song, H.; Cui, Z.; Du, L.; Liao, S. Recent advances in nanostructured transition metal nitrides for fuel cells. Journal of Materials Chemistry A 2020, 8, 20803-20818.

22. Ham, D.; Lee, J. Transition Metal Carbides and Nitrides as Electrode Materials for Low Temperature Fuel Cells. Energies 2009, 2, 873-899.

23. Chen, W. F.; Muckerman, J. T.; Fujita, E. Recent developments in transition metal carbides and nitrides as hydrogen evolution electrocatalysts. Chem Commun (Camb) 2013, 49, 8896-909.

24. Yin, J.; Wang, J.; Ma, Y.; Yu, J.; Zhou, J.; Fan, Z. Recent Advances in the Controlled Synthesis and Catalytic Applications of TwoDimensional Rhodium Nanomaterials. ACS Materials Letters 2020, 3, 121-133.

25. Arico, A. S.; Bruce, P.; Scrosati, B.; Tarascon, J. M.; Van Schalkwijk, W. Nanostructured materials for advanced energy conversion and storage devices. Nat. Mater. 2005, 4, 366-377.

26. Debe, M. K. Electrocatalyst approaches and challenges for automotive fuel cells. Nature 2012, 486, 43-51.

27. Dong, S.; Chen, X.; Zhang, X.; Cui, G. Nanostructured transition metal nitrides for energy storage and fuel cells. Coordination Chemistry Reviews 2013, 257, 1946-1956.

28. Peng, X.; Pi, C.; Zhang, X.; Li, S.; Huo, K.; Chu, P. K. Recent progress of transition metal nitrides for efficient electrocatalytic water splitting. Sustainable Energy $\mathcal{E}$ Fuels 2019, 3, 366-381.

29. Liu, W.; Li, A. Q.; Wu, H. D.; Long, Y.; Huang, J. W.; Deng, X.; Wang, C. Y.; Wang, Q. M.; Wu, S. H. Effects of gas pressure on microstructure and performance of $(\mathrm{Ti}, \mathrm{Al}, \mathrm{Zr}) \mathrm{N}$ coatings produced by physical vapor deposition. Ceram. Int. 2016, 42, 1743617441.

30. Zhu, P. W.; He, Z.; Zhao, Y. N.; Li, D. M.; Liu, H. W.; Zou, G. T. Preparation of high-pressure phase boron nitride films by physical vapor deposition. Journal of Vacuum Science \& Technology a-Vacuum Surfaces and Films 2002, 20, $622-624$.

31. Wei, B.; Tang, G.; Liang, H.; Qi, Z.; Zhang, D.; Hu, W.; Shen, H.; Wang, Z. Bimetallic vanadium-molybdenum nitrides using magnetron co-sputtering as alkaline hydrogen evolution catalyst. Electrochemistry Communications 2018, 93, 166-170.

32. Murthy, A. P.; Govindarajan, D.; Theerthagiri, J.; Madhavan, J.; Parasuraman, K. Metal-doped molybdenum nitride films for enhanced hydrogen evolution in near-neutral strongly buffered aerobic media. Electrochimica Acta 2018, 283, $1525-1533$.

33. Soo Kang, J.; Park, M.-A.; Kim, J.-Y.; Ha Park, S.; Young Chung, D.; Yu, S.-H.; Kim, J.; Park, J.; Choi, J.-W.; Jae Lee, K.; Jeong, J.; Jae Ko, M.; Ahn, K.-S.; Sung, Y.-E. Reactively sputtered nickel nitride as electrocatalytic counter electrode for dye- and quantum dot-sensitized solar cells. Scientific Reports 2015, 5.

34. Uchida, H.; Yamashita, M.; Hanaki, S.; Ueta, T. Characterization of (Ti, Al)N films prepared by ion mixing and vapor deposition. Materials Science and Engineering: A 2004, 387-389, 758-762.

35. Kafizas, A.; Carmalt, C. J.; Parkin, I. P. CVD and precursor chemistry of transition metal nitrides. Coordination Chemistry Reviews 2013, 257, 2073-2119.

36. Shi, J.; Jiang, B. L.; Li, C.; Yan, F. Y.; Wang, D.; Yang, C.; Wan, J. J. Review of Transition Metal Nitrides and Transition Metal Nitrides/Carbon nanocomposites for supercapacitor electrodes. Materials Chemistry and Physics 2020, $245,122533$.

37. Aslanzadeh, S. A. Transition metal-metal oxide hybrids as versatile materials for hydrogen storage. Chin. J. Phys. 2018, 56, 19171924.

38. Ningthoujam, R. S.; Gajbhiye, N. S. Synthesis, electron transport properties of transition metal nitrides and applications. Progress in Materials Science 2015, 70, 50-154.

39. Peng, X.; Huo, K.; Fu, J.; Gao, B.; Wang, L.; Hu, L.; Zhang, X.; Chu, P. K. Porous Dual-Layered MoOxNanotube Arrays with Highly Conductive TiN Cores for Supercapacitors. ChemElectroChem 2015, 2, 512-517.

40. Nagai, M. Transition-metal nitrides for hydrotreating catalyst-Synthesis, surface properties, and reactivities. Applied Catalysis A: General 2007, 322, 178-190.

41. Jiang, Y.; Dong, J.; Tan, S.; Wei, Q.; Xiong, F.; Yang, W.; Shen, Y.; Zhang, Q.; Liu, Z. a.; An, Q.; Mai, L. Surface pseudocapacitance of mesoporous $\mathrm{Mo}_{3} \mathrm{~N}_{2}$ nanowire anode toward reversible high-rate sodium-ion storage. Journal of Energy Chemistry 2021, 55, 295-303.

42. Yang, M.; DiSalvo, F. J. Template-Free Synthesis of Mesoporous Transition Metal Nitride Materials from Ternary Cadmium Transition Metal Oxides. Chemistry of Materials 2012, 24, 4406-4409.

43. Cheng, Z.; Saad, A.; Guo, H.; Wang, C.; Liu, S.; Thomas, T.; Yang, M. Ordered mesoporous transition metal nitrides prepared through hard template nanocasting and rapid nitridation process. Journal of Alloys and Compounds 2020, 838, 155375.

44. Wang, H.; Wu, Z.; Kong, J.; Wang, Z.; Zhang, M. Synthesis of transition metal nitride by nitridation of metastable oxide precursor. Journal of Solid State Chemistry 2012, 194, 238-244. 
45. Choi, D.; Kumta, P. N. Synthesis, Structure, and Electrochemical Characterization of Nanocrystalline Tantalum and Tungsten Nitrides. Journal of the American Ceramic Society 2007, 90, 3113-3120.

46. Afanasiev, P.; Laurenti, D. CCl4-Assisted Preparation of Highly Dispersed Molybdenum and Tungsten Nitrides. Topics in Catalysis 2012, 55, 940-949.

47. Cheng, F.; Kelly, S. M.; Young, N. A.; Clark, S.; Francesconi, M. G.; Lefebvre, F.; Bradley, J. S. General method of preparation of mesoporous $\mathrm{M} / \mathrm{Si}_{3} \mathrm{~N}_{4}$ nano-composites via a non-aqueous sol-gel route. Chem Commun (Camb) 2005, 5662-5664.

48. Qiu, Y.; Gao, L. Metal-urea complex - A precursor to metal nitrides. Journal of the American Ceramic Society 2004, 87, $352-357$.

49. Weil, K. S.; Kumta, P. N. Synthesis of transition metal nitride powders and coatings using alkanolamine chelated precursors. Materials \& Design 2001, 22, 605-615.

50. Sheng, J. P.; Wang, L. Q.; Deng, L.; Zhang, M.; He, H. C.; Zeng, K.; Tang, F. Y.; Liu, Y. N. MOF-Templated Fabrication of Hollow Co4N@N-Doped Carbon Porous Nanocages with Superior Catalytic Activity. ACS Appl. Mater. Interfaces 2018, 10, 7191-7200.

51. Feng, X.; Wang, H.; Bo, X.; Guo, L. Bimetal-Organic Framework-Derived Porous Rodlike Cobalt/Nickel Nitride for All-pH Value Electrochemical Hydrogen Evolution. ACS Appl Mater Interfaces 2019, 11, 8018-8024.

52. Kang, B. K.; Im, S. Y.; Lee, J.; Kwag, S. H.; Kwon, S. B.; Tiruneh, S.; Kim, M. J.; Kim, J. H.; Yang, W. S.; Lim, B.; Yoon, D. H. Insitu formation of MOF derived mesoporous $\mathrm{CO}_{3} \mathrm{~N} /$ amorphous $\mathrm{N}$-doped carbon nanocubes as an efficient electrocatalytic oxygen evolution reaction. Nano Res. 2019, 12, 1605-1611.

53. Cheng, Z.; Saad, A.; Adimi, S.; Guo, H.; Liu, S.; Thomas, T.; Yang, M. Metal organic framework-derived porous Fe 2 N nanocubes by rapid-nitridation for efficient photocatalytic hydrogen evolution. Materials Advances 2020, 1, 1161-1167.

54. Zhu, J.; Liu, C.; Sun, J.; Xing, Y.; Quan, B.; Li, D.; Jiang, D. Interfacial engineering of Co3FeN embedded N-doped carbon nanoarray derived from metal-organic frameworks for enhanced oxygen evolution reaction. Electrochimica Acta 2020, 354, 136629.

55. Hu, Y.; Li, C.; Xi, S.; Deng, Z.; Liu, X.; Cheetham, A. K.; Wang, J. Direct Pyrolysis of a Manganese-Triazolate Metal-Organic Framework into Air-Stable Manganese Nitride Nanoparticles. Adv Sci (Weinh) 2021, 8, 2003212.

56. Wang, F.; Zhao, H.; Ma, Y.; Yang, Y.; Li, B.; Cui, Y.; Guo, Z.; Wang, L. Core-shell-structured Co@Co4N nanoparticles encapsulated into MnO-modified porous N-doping carbon nanocubes as bifunctional catalysts for rechargeable $\mathrm{Zn}$-air batteries. Journal of Energy Chemistry 2020, 50, 52-62.

57. Liu, S.; Huo, Q.; Chen, R.; Chen, P.; Li, Y.; Han, Y. Synthesis and Characterization of an Iron Nitride Constructed by a Novel Template of Metal Organic Framework. Journal of Spectroscopy 2015, 2015, 1-8.

58. Barker, M. G.; Francesconi, M. G.; O'Meara, P. M.; Baker, C. F. New synthetic routes to transition metal ternary nitrides and sulfides. Journal of Alloys and Compounds 2001, 317, 186-189.

59. Xiao, X.; Urbankowski, P.; Hantanasirisakul, K.; Yang, Y.; Sasaki, S.; Yang, L.; Chen, C.; Wang, H.; Miao, L.; Tolbert, S. H.; Billinge, S. J. L.; Abruña, H. D.; May, S. J.; Gogotsi, Y. Scalable Synthesis of Ultrathin $\mathrm{Mn}_{3} \mathrm{~N}_{2}$ Exhibiting Room - Temperature Antiferromagnetism. Advanced Functional Materials 2019, 29, 1809001.

60. Yao, W.; Makowski, P.; Giordano, C.; Goettmann, F. Synthesis of early-transition-metal carbide and nitride nanoparticles through the urea route and their use as alkylation catalysts. Chemistry 2009, 15, 11999-2004.

61. Jia, X.; Zhao, Y.; Chen, G.; Shang, L.; Shi, R.; Kang, X.; Waterhouse, G. I. N.; Wu, L.-Z.; Tung, C.-H.; Zhang, T. NizFeN Nanoparticles Derived from Ultrathin NiFe-Layered Double Hydroxide Nanosheets: An Efficient Overall Water Splitting Electrocatalyst. Advanced Energy Materials 2016, 6, 1502585.

62. Jiang, M.; Li, Y.; Lu, Z.; Sun, X.; Duan, X. Binary nickel-iron nitride nanoarrays as bifunctional electrocatalysts for overall water splitting. Inorganic Chemistry Frontiers 2016, 3, 630-634.

63. Ghimbeu, C. M.; Raymundo-Piñero, E.; Fioux, P.; Béguin, F.; Vix-Guterl, C. Vanadium nitride/carbon nanotube nanocomposites as electrodes for supercapacitors. Journal of Materials Chemistry 2011, 21, 13268-13275.

64. Khazaei, M.; Arai, M.; Sasaki, T.; Chung, C.-Y.; Venkataramanan, N. S.; Estili, M.; Sakka, Y.; Kawazoe, Y. Novel Electronic and Magnetic Properties of Two-Dimensional Transition Metal Carbides and Nitrides. Advanced Functional Materials 2013, 23, 21852192.

65. Salamat, A.; Hector, A. L.; Kroll, P.; McMillan, P. F. Nitrogen-rich transition metal nitrides. Coordination Chemistry Reviews 2013, 257, 2063-2072.

66. Zhongwei Chen, D. H., Aiping Yu,Lei Zhang and Jiujun Zhang. A review on non-precious metal electrocatalysts for PEM fuel cells. Energy Environ. Sci. 2011, 4, 3167-3192

67. Chi, B.; Zhang, X.; Liu, M.; Jiang, S.; Liao, S. Applications of M/N/C analogue catalysts in PEM fuel cells and metal-air/oxygen batteries: Status quo, challenges and perspectives. Progress in Natural Science: Materials International 2020, 30, 807-814.

68. Jasinski. A New Fuel Cell Cathode Catalyst Nature 1964, 201 (4925) 1212-1213.

69. Yang, M. H.; Guarecuco, R.; DiSalvo, F. J. Mesoporous Chromium Nitride as High Performance Catalyst Support for Methanol Electrooxidation. Chem. Mat. 2013, 25, 1783-1787.

70. Zheng, Y.; Zhang, J.; Zhan, H.; Sun, D.; Dang, D.; Tian, X. L. Porous and three dimensional titanium nitride supported platinum as an electrocatalyst for oxygen reduction reaction. Electrochemistry Communications 2018, 91, 31-35.

71. Yue, R.; Xia, M.; Wang, M.; Chen, P.; Gong, W.; Liao, S.; Li, Z.; Gao, F.; Zhang, L.; Wang, J. TiN and TiC as stable and promising 
supports for oxygen reduction reaction: Theoretical and experimental study. Applied Surface Science 2019, 495, 143620.

72. Qi, J.; Jiang, L. H.; Jiang, Q. A.; Wang, S. L.; Sun, G. Q. Theoretical and Experimental Studies on the Relationship between the Structures of Molybdenum Nitrides and Their Catalytic Activities toward the Oxygen Reduction Reaction. J. Phys. Chem. C 2010, 114, 18159-18166.

73. Zhang, H.; Liu, M.; Cheng, W.; Li, Y.; Zhou, W.; Su, H.; Zhao, X.; Yao, P.; Liu, Q. Metallic Ni3N Quantum Dots as a Synergistic Promoter for NiO Nanosheet toward Efficient Oxygen Reduction Electrocatalysis. The Journal of Physical Chemistry C 2019, 123, 8633-8639.

74. Luo, J.; Tian, X.; Zeng, J.; Li, Y.; Song, H.; Liao, S. Limitations and Improvement Strategies for Early-Transition-Metal Nitrides as Competitive Catalysts toward the Oxygen Reduction Reaction. ACS Catalysis 2016, 6, 6165-6174.

75. Tian, X.; Luo, J.; Nan, H.; Fu, Z.; Zeng, J.; Liao, S. Binary transition metal nitrides with enhanced activity and durability for the oxygen reduction reaction. Journal of Materials Chemistry A 2015, 3, 16801-16809.

76. Tian, X. L.; Wang, L.; Chi, B.; Xu, Y.; Zaman, S.; Qi, K.; Liu, H.; Liao, S.; Xia, B. Y. Formation of a Tubular Assembly by Ultrathin Ti $0.8 \mathrm{Co} 0.2 \mathrm{~N}$ Nanosheets as Efficient Oxygen Reduction Electrocatalysts for Hydrogen-/Metal-Air Fuel Cells. ACS Catalysis 2018, 8, 8970-8975.

77. Li, W.; Pan, Z.; Huang, Z.; Zhou, Q.; Xu, Y.; Wu, S.; Chen, C.; Lin, Y.; Hu, G. Pt nanoparticles supported on titanium iron nitride nanotubes prepared as a superior electrocatalysts for methanol electrooxidation. International Journal of Hydrogen Energy 2018, 43, 9777-9786.

78. Varga, T.; Vasarhelyi, L.; Ballai, G.; Haspel, H.; Oszko, A.; Kukovecz, A.; Konya, Z. Noble-Metal-Free Iron Nitride/NitrogenDoped Graphene Composite for the Oxygen Reduction Reaction. ACS Omega 2019, 4, 130-139.

79. Lu, X.; Zhao, C. Electrodeposition of hierarchically structured three-dimensional nickel-iron electrodes for efficient oxygen evolution at high current densities. Nat Commun 2015, 6, 6616.

80. Zhong, Y.; Xia, X.; Shi, F.; Zhan, J.; Tu, J.; Fan, H. J. Transition Metal Carbides and Nitrides in Energy Storage and Conversion. Adv Sci (Weinh) 2016, 3, 1500286.

81. Chen, P.; Xu, K.; Fang, Z.; Tong, Y.; Wu, J.; Lu, X.; Peng, X.; Ding, H.; Wu, C.; Xie, Y. Metallic Co4N Porous Nanowire Arrays Activated by Surface Oxidation as Electrocatalysts for the Oxygen Evolution Reaction. Angew Chem Int Ed Engl 2015, 54, 1471014714.

82. Zhang, Y.; Ouyang, B.; Xu, J.; Jia, G.; Chen, S.; Rawat, R. S.; Fan, H. J. Rapid Synthesis of Cobalt Nitride Nanowires: Highly Efficient and Low-Cost Catalysts for Oxygen Evolution. Angew Chem Int Ed Engl 2016, 55, 8670-8674.

83. Xu, K.; Chen, P.; Li, X.; Tong, Y.; Ding, H.; Wu, X.; Chu, W.; Peng, Z.; Wu, C.; Xie, Y. Metallic nickel nitride nanosheets realizing enhanced electrochemical water oxidation. J Am Chem Soc 2015, 137, 4119-4125.

84. Zeng, X.; Choi, S. M.; Bai, Y.; Jang, M. J.; Yu, R.; Cho, H.-S.; Kim, C.-H.; Myung, N. V.; Yin, Y. Plasmon-Enhanced Oxygen Evolution Catalyzed by Fe2N-Embedded TiOxNy Nanoshells. ACS Applied Energy Materials 2019, 3, $146-151$.

85. Wang, Y.; Zhang, B.; Pan, W.; Ma, H.; Zhang, J. 3 D Porous Nickel-Cobalt Nitrides Supported on Nickel Foam as Efficient Electrocatalysts for Overall Water Splitting. ChemSusChem 2017, 10, 4170-4177.

86. Gao, X.; Yu, Y.; Liang, Q.; Pang, Y.; Miao, L.; Liu, X.; Kou, Z.; He, J.; Pennycook, S. J.; Mu, S.; Wang, J. Surface nitridation of nickel-cobalt alloy nanocactoids raises the performance of water oxidation and splitting. Applied Catalysis B: Environmental 2020, $270,118889$.

87. Li, D.; Xing, Y.; Yang, R.; Wen, T.; Jiang, D.; Shi, W.; Yuan, S. Holey Cobalt-Iron Nitride Nanosheet Arrays as High-Performance Bifunctional Electrocatalysts for Overall Water Splitting. ACS Appl Mater Interfaces 2020, 12, 29253-29263.

88. Liu, T.; Li, M.; Bo, X.; Zhou, M. Comparison Study toward the Influence of the Second Metals Doping on the Oxygen Evolution Activity of Cobalt Nitrides. ACS Sustainable Chemistry \& Engineering 2018, 6, 11457-11465.

89. Sun, H.; Tian, C.; Fan, G.; Qi, J.; Liu, Z.; Yan, Z.; Cheng, F.; Chen, J.; Li, C. P.; Du, M. Boosting Activity on Co4N Porous Nanosheet by Coupling $\mathrm{CeO}_{2}$ for Efficient Electrochemical Overall Water Splitting at High Current Densities. Advanced Functional Materials 2020, 30, 1910596.

90. Kwag, S. H.; Lee, Y. S.; Lee, J.; Jeong, D. I.; Kwon, S. B.; Yoo, J. H.; Woo, S.; Lim, B. S.; Park, W. K.; Kim, M.-J.; Kim, J. H.; Lim, B.; Kang, B. K.; Yang, W. S.; Yoon, D. H. Design of 2D Nanocrystalline $\mathrm{Fe}_{2} \mathrm{Ni}_{2} \mathrm{~N}$ Coated onto Graphene Nanohybrid Sheets for Efficient Electrocatalytic Oxygen Evolution. ACS Applied Energy Materials 2019, 2, 8502-8510.

91. Liang, S.; Jing, M.; Pervaiz, E.; Guo, H.; Thomas, T.; Song, W.; Xu, J.; Saad, A.; Wang, J.; Shen, H.; Liu, J.; Yang, M. Nickel-Iron Nitride-Nickel Sulfide Composites for Oxygen Evolution Electrocatalysis. ACS Appl Mater Interfaces 2020, 12, 41464-41470.

92. Li, R.; Xu, C.; Jiang, X.; Bando, Y.; Wang, X. Porous Monolithic Electrode of $\mathrm{Ni}_{(3)} \mathrm{FeN}$ on 3D Graphene for Efficient Oxygen Evolution. J Nanosci Nanotechnol 2020, 20, 5175-5181.

93. Wang, J.; Cao, F.; Shen, C.; Li, G.; Li, X.; Yang, X.; Li, S.; Qin, G. Nanoscale nickel-iron nitride-derived efficient electrochemical oxygen evolution catalysts. Catalysis Science \& Technology 2020, 10, 4458-4466.

94. Jia, J.; Zhai, M.; Lv, J.; Zhao, B.; Du, H.; Zhu, J. Nickel Molybdenum Nitride Nanorods Grown on Ni Foam as Efficient and Stable Bifunctional Electrocatalysts for Overall Water Splitting. ACS Appl Mater Interfaces 2018, 10, 30400-30408.

95. Xie, B.; Zhang, Y.; Zhang, R. Coassembly and high ORR performance of monodisperse Pt nanocrystals with a mesopore-rich nitrogen-doped graphene aerogel. Journal of Materials Chemistry A 2017, 5, 17544-17548. 
96. Cherevko, S.; Geiger, S.; Kasian, O.; Kulyk, N.; Grote, J.-P.; Savan, A.; Shrestha, B. R.; Merzlikin, S.; Breitbach, B.; Ludwig, A.; Mayrhofer, K. J. J. Oxygen and hydrogen evolution reactions on $\mathrm{Ru}, \mathrm{RuO}_{2}$, $\mathrm{Ir}$, and $\mathrm{IrO}_{2}$ thin film electrodes in acidic and alkaline electrolytes: A comparative study on activity and stability. Catalysis Today 2016, 262, 170-180.

97. Fan, Y.; Ida, S.; Staykov, A.; Akbay, T.; Hagiwara, H.; Matsuda, J.; Kaneko, K.; Ishihara, T. Ni-Fe Nitride Nanoplates on NitrogenDoped Graphene as a Synergistic Catalyst for Reversible Oxygen Evolution Reaction and Rechargeable Zn-Air Battery. Small 2017, 13, 1700099.

98. Wang, Q.; Shang, L.; Shi, R.; Zhang, X.; Waterhouse, G. I. N.; Wu, L.-Z.; Tung, C.-H.; Zhang, T. 3D carbon nanoframe scaffoldimmobilized $\mathrm{Ni}_{3} \mathrm{FeN}$ nanoparticle electrocatalysts for rechargeable zinc-air batteries' cathodes. Nano Energy 2017, 40, 382-389.

99. Zhang, N.; Xie, S.; Wang, W.; Xie, D.; Zhu, D.; Cheng, F. Ultra-Small Fe2N/N-CNTs as Efficient Bifunctional Catalysts for Rechargeable Zn-Air Batteries. Journal of The Electrochemical Society 2020, 167, 020505.

100. Fu, G.; Cui, Z.; Chen, Y.; Xu, L.; Tang, Y.; Goodenough, J. B. Hierarchically mesoporous nickel-iron nitride as a cost-efficient and highly durable electrocatalyst for Zn-air battery. Nano Energy 2017, 39, 77-85.

101. Wu, Z.; Wang, H.; Xiong, P.; Li, G.; Qiu, T.; Gong, W. B.; Zhao, F.; Li, C.; Li, Q.; Wang, G.; Geng, F. Molecularly Thin Nitride Sheets Stabilized by Titanium Carbide as Efficient Bifunctional Electrocatalysts for Fiber-Shaped Rechargeable Zinc-Air Batteries. Nano Lett 2020, 20, 2892-2898.

102. Cui, Z.; Fu, G.; Li, Y.; Goodenough, J. B. Ni3 FeN-Supported Fe3 Pt Intermetallic Nanoalloy as a High-Performance Bifunctional Catalyst for Metal-Air Batteries. Angew Chem Int Ed Engl 2017, 56, 9901-9905.

103. Emerilis Casado-Rivera, D. J. V., Laif Alden, Cora Lind, Craig Downie,Terannie Va'zquez-Alvarez, Antonio C. D. Angelo, Francis J. DiSalvo, andHe' ctor D. Abrun ${ }^{*}{ }^{*}$, Electrocatalytic Activity of Ordered Intermetallic Phases for Fuel Cell Applications. AM. CHEM. SOC. 2004, 126, 4043-4049.

104. Davari, E.; Ivey, D. G. Synthesis and electrochemical performance of manganese nitride as an oxygen reduction and oxygen evolution catalyst for zinc-air secondary batteries. Journal of Applied Electrochemistry 2017, 47, 815-827.

105. Miura, A.; Rosero-Navarro, C.; Masubuchi, Y.; Higuchi, M.; Kikkawa, S.; Tadanaga, K. Nitrogen-Rich Manganese Oxynitrides with Enhanced Catalytic Activity in the Oxygen Reduction Reaction. Angew Chem Int Ed Engl 2016, 55, 7963-7967.

106. Chen, L.; Zhang, Y.; Liu, X.; Long, L.; Wang, S.; Xu, X.; Liu, M.; Yang, W.; Jia, J. Bifunctional oxygen electrodes of homogeneous Co4N nanocrystals@N-doped carbon hybrids for rechargeable Zn-air batteries. Carbon 2019, 151, 10-17.

107. Guan, Y.; Liu, G.; Li, J.; Wang, Y.; Zhang, Z. Surface-engineered cobalt nitride composite as efficient bifunctional oxygen electrocatalyst. Nanotechnology 2019, 30, 495406.

108. Gao, T.; Jin, Z.; Zhang, Y.; Tan, G.; Yuan, H.; Xiao, D. Coupling cobalt-iron bimetallic nitrides and N-doped multi-walled carbon nanotubes as high-performance bifunctional catalysts for oxygen evolution and reduction reaction. Electrochimica Acta 2017, 258, 51-60.

109. Jiang, J.; Li, Y.; Liu, J.; Huang, X.; Yuan, C.; Lou, X. W. Recent advances in metal oxide-based electrode architecture design for electrochemical energy storage. Adv Mater 2012, 24, 5166-5180.

110. Zhang, Y.; Gao, T.; Jin, Z.; Chen, X.; Xiao, D. A robust water oxidation electrocatalyst from amorphous cobalt-iron bimetallic phytate nanostructures. Journal of Materials Chemistry A 2016, 4, 15888-15895. 